\title{
Distribution Law and Prediction Model of Dust Concentration under Airflow Adjustment in Fully Mechanized Heading Face
}

\author{
Xiaoyan Gong $\mathbb{D}^{1},{ }^{1}$ Congcong Jia $\left(\mathbb{D},{ }^{1}\right.$ Kang Sun, ${ }^{1}$ Jian Cui, ${ }^{1}$ Kefan Lei, \\ Yuxuan Xue, ${ }^{2}$ and He Xue $\mathbb{D}^{1}$ \\ ${ }^{1}$ Xian University of Science and Technology, Xian 710054, China \\ ${ }^{2}$ The University of Hong Kong, Pokfulam 999077, Hong Kong \\ Correspondence should be addressed to Xiaoyan Gong; gongxymail@163.com
}

Received 11 April 2019; Accepted 1 July 2019; Published 21 July 2019

Academic Editor: Zhengbiao Peng

Copyright (C) 2019 Xiaoyan Gong et al. This is an open access article distributed under the Creative Commons Attribution License, which permits unrestricted use, distribution, and reproduction in any medium, provided the original work is properly cited.

\begin{abstract}
The current situation of extensive ventilation management for the fully mechanized heading face cannot dynamically control air velocity and make reasonable dust migration distribution, resulting in serious disaster of dust and environmental pollution in the roadway. In this paper, the fluid mechanics, finite element numerical simulation, and underground measurement were combined to analyze the distribution of dust concentration under the variable airflow state at the duct outlet to obtain the massive correlation data of duct outlet parameters and dust concentration. For the pedestrian breathing-height in the backflow side and driver location, the double-objective BP prediction model for dust concentration under airflow adjustment was established, and the performance parameters and prediction accuracy of the BP prediction model were analyzed by using the relative error and fitting analysis. In Ningtiaota coal mine, located in Northern Shaanxi province of China, the self-developed control device is installed on the duct outlet with underground test and application verification to refine the model. The results indicated the dynamic control of airflow optimizes dust concentration distribution. The dust concentration at the pedestrian breathing-height in the backflow side and driver location was significantly decreased after the installation of adjustment device. Dust concentration at the pedestrian breathing-height and driver location was decreased by $31 \%$ and 34\%, respectively, compared with the results before adjustment, which achieved the safe, environment-friendly, and energy-saving ventilation and the dust removal function in fully mechanized heading face.
\end{abstract}

\section{Introduction}

With the continuous breakthroughs of cross section size, driving speed, and the length of coal roadway, the traditionally extensive control and mode of ventilation become inadequate to meet the requirements with higher security level, efficient and environmental protection [1-3]. In the process of excavation, the airflow cannot be dynamically regulated according to actual ventilation demand, resulting in the unreasonable airflow distribution; besides, dust concentration reaches $1500 \mathrm{mg} / \mathrm{m}^{3}$, which is far exceeding the standard required by The Coal Mine Safety Regulations of $4 \mathrm{mg} / \mathrm{m}^{3}[4,5]$, causing the dust explosion accidents and pollution risks. If the air supply demand is configured according to the initial stage of excavation, the wind energy loss will increase as the roadway extended under the specific ventilation scheme and air volume, and the air velocity often fails to meet the requirements of the regulations, which cause the problem of serious dust accumulation. If it is configured according to the maximum demand, the air velocity will be too large in the initial stage of excavation and exceed the specified range, which causes discomfort feelings of workers, secondary blowing dust, and serious pollution at breathing-height area [6-9]. At present, many researchers have shown that the duct position, diameter, and distance from the duct outlet to heading face have a great influence on the distribution of dust concentration [10-16]. In the research, the authors found that the change of airflow state at the duct outlet has a significant effect on controlling dust migration distribution and creatively put forward a new method to optimize the distribution of airflow, gas, and dust fields by dynamic adjustment of airflow 


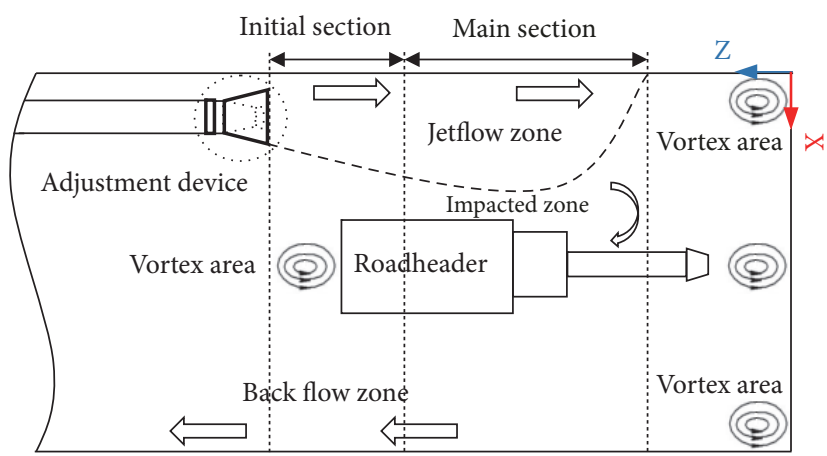

(a)

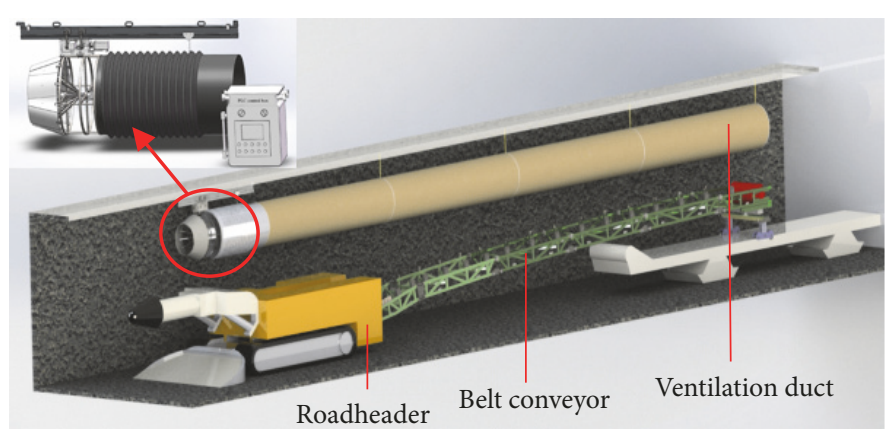

(b)

FIGURE 1: Schematic diagram of airflow structure and installation position of the adjustment device. (a) Schematic diagram of airflow structure. (b) Installation position of the adjustment device.

[17-20]. The new control device for airflow adjustment at the duct outlet is developed [21], and the installation position is shown in Figure 1. According to the theory of fluid mechanics, numerical simulation and underground measurement method, analyzing the influence of airflow adjustment on dust concentration distribution, and the correlation mechanism among airflow adjustment parameters, air velocity and dust concentration are established. Based on the large amount of sample data obtained, the BP neural network algorithm is used for data mining $[22,23]$; then, the dust safety hazard and pollution comprehensive prediction neural network model and optimal adjustment scheme are established. In the coal-bearing coal mine of the Shaanxi Coal Group, the self-developed control device is used for the underground installation test and application. Hence, the distribution of dust concentration under airflow adjustment and the accuracy of neural network prediction model are verified, which provides a new theoretical basis for the safe, environment-friendly, and efficient ventilation in fully mechanized heading face.

\section{Analysis Methods of Airflow and Dust Field}

\subsection{Theoretical Analysis}

(1) Airflow Field. The airflow motion in the roadway complies with the law of the physical conservation. It is assumed that there is no heat source in the roadway, and the thermal radiation from the wall is not considered. The airflow motion meets the law of mass conservation and momentum conservation, which are embodied as the commonly used continuity equation and the N-S equation in the fluid mechanics. The airflow is treated as the incompressible continuous phase; therefore the continuity equation can be expressed as

$$
\frac{\partial \rho}{\partial t}+\frac{\partial}{\partial x_{i}}\left(\rho u_{i}\right)=0
$$

For a control volume, the fluid element motion obeys Newton's second law; therefore the N-S equation of the incompressible viscous fluid can be described by

$$
\rho \frac{d u}{d t}=\rho f-\nabla p+\mu \nabla^{2} u
$$

Among them, $\nabla^{2}=\partial^{2} / \partial x_{1}^{2}+\partial^{2} / \partial x_{2}^{2}+\partial^{2} / \partial x_{3}^{2}$. Considering that the airflow is incompressible ideal fluid, $\nabla \bullet u=0, \mu=0$. Then, (2) can be simplified as follows:

$$
\frac{\partial u}{\partial t}+(u \cdot \nabla)=f-\frac{1}{\rho} \nabla p+v \nabla^{2} u
$$

where $\rho\left(\mathrm{kg} / \mathrm{m}^{3}\right)$ is the air density, $t(s)$ is the time, $u(\mathrm{~m} / \mathrm{s})$ is the air velocity, $u_{i}(\mathrm{~m} / \mathrm{s})$ is the velocity of the surrounding fluid, $p(P a)$ is the hydrostatic pressure, and $\mu(P a \bullet s)$ is the dynamic viscosity of air.

(2) Dust Field. In dust field, the dust emission source is set at the heading face, and its injection type is dynamic according to the specific cutting mode and sequence of the roadheader. The dust particles are considered as discrete phase, and air flows continuously. The Euler-Lagrange method is used to simulate the distribution of airflow and dust migration under the dynamic change of the dust emission source. The force among dust particles is neglected, but dust particles themselves should be loaded with gravity, buoyancy, drag force, etc. Therefore, gas-solid two-phase flow mathematical model is used to analyze the dust migration law. The unit mass dust motion equation in the Lagrangian coordinate system can be expressed as

$$
\frac{d u_{p}}{d t}=F_{D}\left(u-u_{p}\right)+\frac{g\left(\rho_{p}-\rho\right)}{\rho_{p}}+F_{s}
$$

Among them, $F_{D}\left(u-u_{p}\right)$ is the unit mass drag force, and $F_{D}$ has the following form, which is shown as

$$
F_{D}=\frac{18 \mu}{\rho_{p} d_{p}^{2}} \frac{C_{D} R e_{p}}{24}
$$




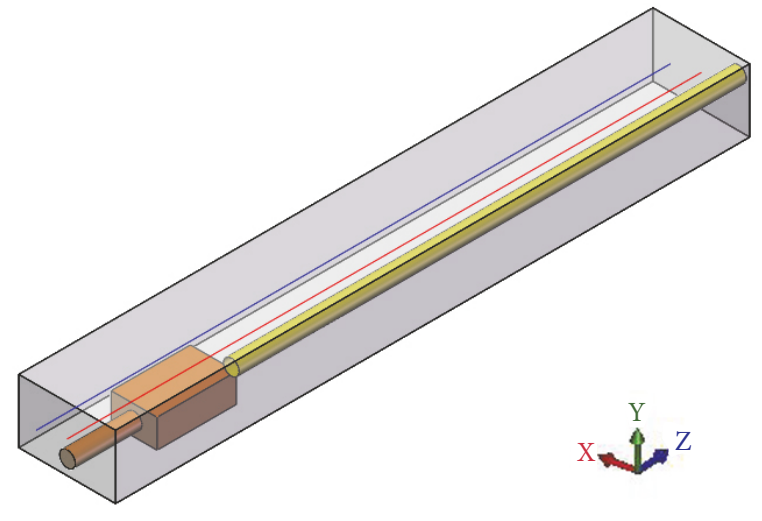

(a)

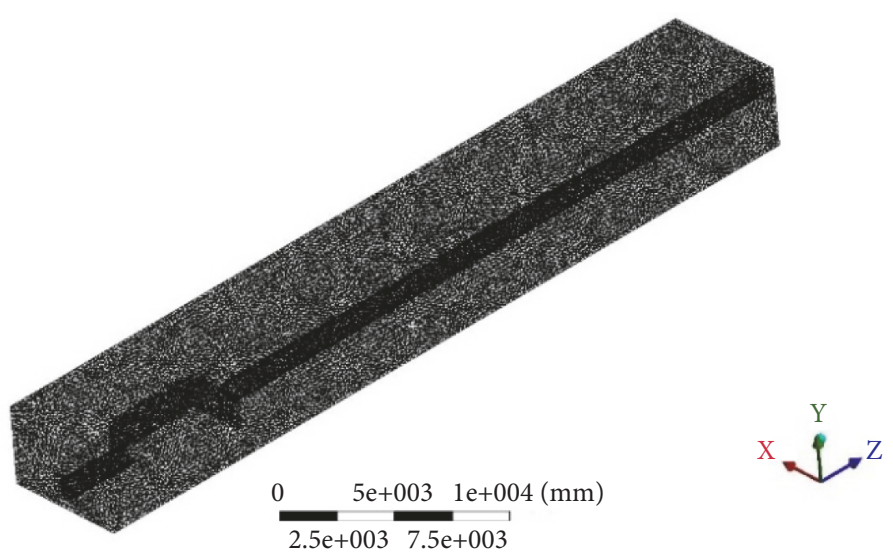

(b)

Figure 2: The finite element model of fully mechanized heading face. (a) Geometric model. (b) Meshing model.

where $F_{D}(N)$ is the drag force, $u_{p}(m / s)$ is the duct particle velocity, $u(\mathrm{~m} / \mathrm{s})$ is the air velocity, $\rho_{p}\left(\mathrm{~kg} / \mathrm{m}^{3}\right)$ is the dust particle density, $\rho\left(\mathrm{kg} / \mathrm{m}^{3}\right)$ is the air density, $F_{s}(N)$ is the Saffman force, $\mu(P a \bullet s)$ is the dynamic viscosity of air, $C_{D}$ is the drag coefficient, $R e_{p}$ is the particle Reynolds number, and $d_{p}(m)$ is the dust particle diameter.

\subsection{Finite Element Analysis Method and Verification. Accord-} ing to the actual condition of the heading face in Ningtiaota coal mine, the finite element model under the dynamic change of dust emission source is established. The geometric model of the roadway is a cuboid of $6.1 \mathrm{~m} \times 4.0 \mathrm{~m} \times 40 \mathrm{~m}$, the diameter of the duct is $1 \mathrm{~m}$, and the distance from the central axis of the duct to the top and side walls is $0.95 \mathrm{~m}$ and 0.7 $\mathrm{m}$. In terms of the roadheader, it is simplified into two parts: the machine part (cuboid) and the cutting part (cylinder). The origin of the coordinate is located on the near-duct side of the boundary between the head section and the bottom plate. The $\mathrm{X}$-axis represents the width of the roadway, the Yaxis represents the height of the roadway, and the negative direction of the $\mathrm{Z}$-axis is the digging direction. The main area of the pedestrian movement in the roadway is represented by two lines, where the red line $(\mathrm{X}=3.05 \mathrm{~m}, \mathrm{Y}=2 \mathrm{~m}$, and $\mathrm{Z}=0$ $40 \mathrm{~m})$ indicates the variation of driver location along the roadway and the blue line $(X=5 \mathrm{~m}, \mathrm{Y}=1.5 \mathrm{~m}$, and $\mathrm{Z}=0 \sim 40 \mathrm{~m})$ indicates the variation of pedestrians location in the backflow side. The finite element model of heading face is shown in Figure 2.

The geometric model is imported into Fluent to set boundary conditions. The end of the outlet is set as speed inlet, the tail section of the roadway is set as outlet with standard atmospheric pressure, and the total air volume is 360 $\mathrm{m}^{3} / \mathrm{min}$, assuming that the walls surface are not slipped, and the airflow is incompressible. The dust emission source is set at the heading face and its injection type is dynamic. The other numerical simulation parameters of airflow and dust field are set as shown in Tables 1 and 2.

In order to verify the accuracy and feasibility of the numerical simulation scheme, the numerical simulation
TABLE 1: Setting of airflow field parameters.

\begin{tabular}{lc}
\hline Condition & Define \\
\hline Inlet Boundary Type & Velocity-inlet \\
Viscous Model & Realizable k- $\varepsilon$ \\
Inlet Velocity Magnitude $(\mathrm{m} / \mathrm{s})$ & 7.64 \\
Turbulence Intensity & $3.08 \%$ \\
Hydraulic Diameter $(\mathrm{m})$ & 1 \\
Outlet Boundary Type & Outflow \\
Gravitational Acceleration $\left(\mathrm{m} / \mathrm{s}^{2}\right)$ & -9.8 \\
\hline
\end{tabular}

TABLE 2: Setting of dust field parameters.

\begin{tabular}{lc}
\hline Condition & Define \\
\hline Turbulent Dispersion & Discrete Random Walk Model \\
Diameter Distribution & Rosin-Rammler \\
Min. Diameter $(\mathrm{m})$ & $1 \mathrm{e}-06$ \\
Max. Diameter $(\mathrm{m})$ & $1 \mathrm{e}-04$ \\
Mid. Diameter $(\mathrm{m})$ & $1.2 \mathrm{e}-05$ \\
Number of Diameters & 10 \\
Spread Parameter & 1.77 \\
Total Flow Rate $(\mathrm{kg} / \mathrm{s})$ & 0.0076 \\
Time Scale Constant & 0.15 \\
\hline
\end{tabular}

results of airflow field and dust field at different distances from the duct outlet to heading face are compared with the data measured in the roadway. Air velocity and dust concentration at the distance of $8 \mathrm{~m}$ are selected as the verification objects, and the measuring points at the pedestrian breathing-height in the backflow side $(\mathrm{X}=5 \mathrm{~m}, \mathrm{Y}=1.5 \mathrm{~m})$ are arranged in the sections of $5 \mathrm{~m}, 7.5 \mathrm{~m}, 10 \mathrm{~m}, 12.5 \mathrm{~m}, 15 \mathrm{~m}, 17.5 \mathrm{~m}$, $20 \mathrm{~m}, 22.5 \mathrm{~m}, 25 \mathrm{~m}$, and $30 \mathrm{~m}$ from the heading face. The simulated data and measured data are shown in Tables 3 and 4 , and the simulated data is compared with the measured data (see Figure 3).

It can be seen from Table 3 and Figure 3(a) that the simulated values are similar to the underground measured 
TABLE 3: Air velocity comparison of measured data and simulated data.

\begin{tabular}{lcccccccccc}
\hline Distance $(\mathrm{m})$ & 5 & 7.5 & 10 & 12.5 & 15 & 17.5 & 20 & 22.5 & 25 & 30 \\
\hline Measured data $(\mathrm{m} / \mathrm{s})$ & 1.52 & - & 0.18 & 0.21 & 0.20 & 0.17 & 0.12 & - & - & 0.14 \\
Simulated data $(\mathrm{m} / \mathrm{s})$ & 1.41 & 0.03 & 0.17 & 0.19 & 0.19 & 0.16 & 0.11 & 0.06 & 0.07 & 0.13 \\
Error rate $(\%)$ & 7.2 & - & 5.6 & 9.5 & 5.0 & 5.9 & 8.3 & - & - \\
\hline
\end{tabular}

TABLE 4: Dust concentration comparison of measured data and simulated data.

\begin{tabular}{lcccccccccc}
\hline Distance $(\mathrm{m})$ & 5 & 7.5 & 10 & 12.5 & 15 & 17.5 & 20 & 22.5 & 25 & 30 \\
\hline Measured data $\left(\mathrm{mg} / \mathrm{m}^{3}\right)$ & 249 & 230 & 246 & 225 & 327 & 258 & 271 & 272 & 304 & 232 \\
Simulated data $\left(\mathrm{mg} / \mathrm{m}^{3}\right)$ & 238 & 218 & 233 & 208 & 314 & 244 & 257 & 254 & 285 & 217 \\
Error rate $(\%)$ & 4.4 & 5.2 & 5.3 & 7.6 & 4.0 & 5.4 & 5.2 & 6.6 & 6.3 & 6.5 \\
\hline
\end{tabular}

Note: "-" means that the air velocity is too small to be tested.

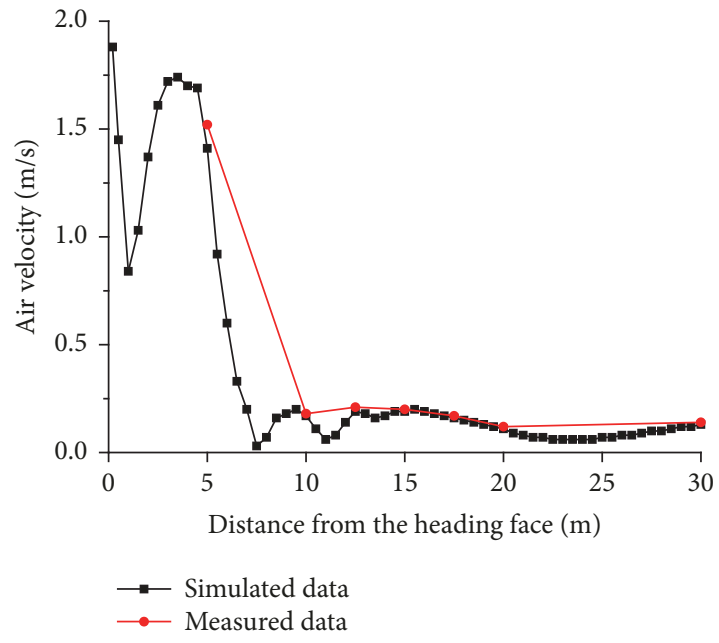

(a)

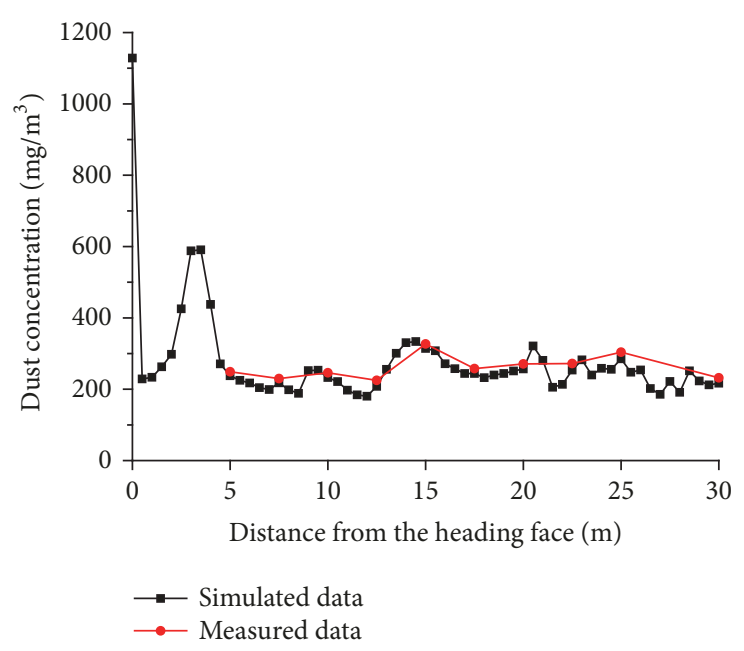

(b)

Figure 3: Comparison of measured data and simulated data. (a) Air velocity along the pedestrian breathing-height. (b) Dust concentration along the pedestrian breathing-height.

values. Although there is a certain error because the actual ventilation is affected by complicated factors such as the roadheader, the error is basically controlled at about $10 \%$, which proves that the numerical simulation of airflow field is feasible. From Table 4 and Figure 3(b), it can be seen that the numerical simulated results are consistent with the measured results, and the error is basically controlled at about $8 \%$, which verifies the feasibility and accuracy of the numerical simulation in the dust field.

\section{Results}

\subsection{Influence of Airflow Adjustment on Air Velocity and Dust Concentration}

3.1.1. Simulation Schemes of Airflow Field and Dust Field. Aiming at the problems of airflow and dust field under the original ventilation condition, the influence of airflow adjustment parameters on the distribution of airflow and dust migration is observed. There are dust pollution and safety hazards at the driver location and backflow side; we found that, at distance of $5 \sim 10 \mathrm{~m}$ from the duct outlet to heading face, the outlet parameters on caliber of $0.7 \sim 1.2 \mathrm{~m}$, horizontal right deviation of $0^{\circ} \sim 25^{\circ}$, and vertical upward deflection of $0^{\circ} \sim 6^{\circ}$, there is a great influence on the distribution of airflow and dust migration in the roadway. In order to analyze influence of airflow adjustment on air velocity and dust concentration, the simulation schemes are designed according to the orthogonal experiment (see Table 5).

3.1.2. Influence of Airflow Adjustment on Air Velocity. The airflow field under the different adjustment schemes is simulated and calculated. Here list the nearest distance of $5 \mathrm{~m}$ and the farthest distance of $10 \mathrm{~m}$ from the duct outlet to heading face, the air velocity along the pedestrian breathing-height in the backflow side $(X=5 \mathrm{~m}, \mathrm{Y}=1.5 \mathrm{~m})$ and the driver's breathingheight $(X=3.05 \mathrm{~m}, \mathrm{Y}=2 \mathrm{~m})$ are shown in Figures 4 and 5 .

It can be seen from Figure 4 that, at the nearest distance of $5 \mathrm{~m}$, the air velocity in some areas has exceeded the most comfortable range of $0.5 \sim 1.0 \mathrm{~m} / \mathrm{s}$, causing discomfort feelings 
TABLE 5: The simulation schemes under airflow adjustment.

\begin{tabular}{|c|c|c|c|c|}
\hline Scheme & $\mathrm{L}(\mathrm{m})$ & $\mathrm{d}(\mathrm{m})$ & $\mathrm{a}\left({ }^{\circ}\right)$ & $\mathrm{b}\left({ }^{\circ}\right)$ \\
\hline 1 & 5 & 1.1 & 5 & 4 \\
\hline 2 & 5 & 1.1 & 10 & 6 \\
\hline 3 & 5 & 1.1 & 15 & 2 \\
\hline 4 & 5 & 1.2 & 5 & 6 \\
\hline 5 & 5 & 1.2 & 10 & 2 \\
\hline 6 & 5 & 1.2 & 15 & 4 \\
\hline 7 & 6 & 1.0 & 5 & 4 \\
\hline$\vdots$ & $\vdots$ & $\vdots$ & $\vdots$ & $\vdots$ \\
\hline 34 & 10 & 0.9 & 5 & 2 \\
\hline 35 & 10 & 0.9 & 10 & 4 \\
\hline 36 & 10 & 0.9 & 15 & 0 \\
\hline
\end{tabular}

where $\mathrm{L}(\mathrm{m})$ represents the distance from the duct outlet to heading face, $\mathrm{d}(\mathrm{m})$ represents the duct outlet caliber, a $\left(^{\circ}\right)$ represents the horizontal right deviation of duct outlet, $\mathrm{b}\left({ }^{\circ}\right)$ represents the vertical upward deflection of duct outlet.

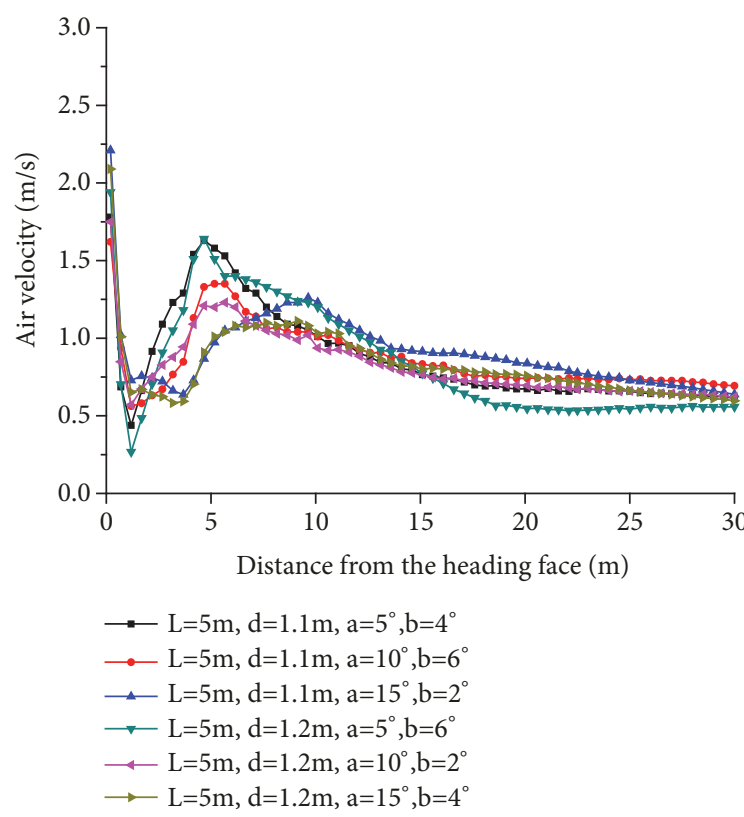

(a)

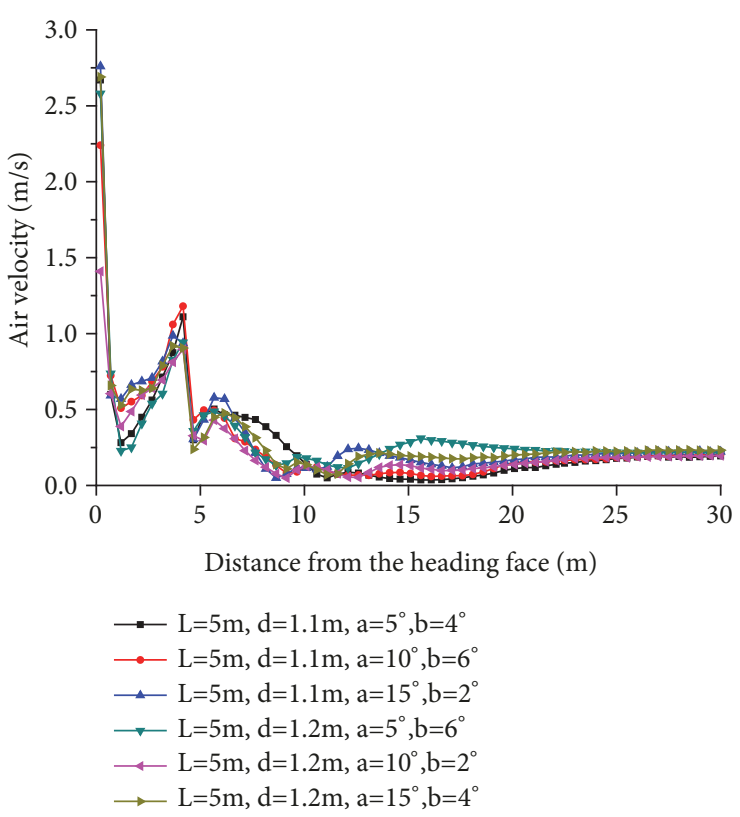

(b)

FIGURE 4: Comparison of air velocity at the nearest distance of $5 \mathrm{~m}$. (a) Air velocity along the pedestrian breathing-height. (b) Air velocity along the driver's breathing-height.

for workers. Increasing the caliber can reduce the air velocity and expand the range of airflow radiation. However, if the caliber is too large, the air velocity will be too low to effectively discharge the dust. Therefore, the caliber should be within a reasonable range. From Figure 5, it can be seen that, at the farthest distance of $10 \mathrm{~m}$, the air velocity is too low, and the air velocity in some areas is even lower than the minimum limit of $0.25 \mathrm{~m} / \mathrm{s}$ specified by The Coal Mine Safety Regulations [24]. By reducing the caliber, the effective range is increased, and the air velocity in the backflow side is increased. But the boundary layer of the jet is too narrow when the caliber is too small, causing dust accumulated. The vertical upward deflection of the duct outlet can effectively reduce dust concentration at the air duct side and the backflow side, and the horizontal right deviation can reduce dust concentration at the backflow side. However, there is a safety hazard of dust accumulation in the air duct side when the horizontal right angle is too large.

3.1.3. Influence of Airflow Adjustment on Dust Concentration. The dust field under different adjustment schemes is simulated and calculated. Here list the nearest distance of $5 \mathrm{~m}$ and the farthest distance of $10 \mathrm{~m}$ from the duct outlet to heading face, dust concentration distribution at pedestrian breathingheight area $(\mathrm{Y}=1.5 \mathrm{~m})$ and driver's breathing-height area $(\mathrm{Y}=2 \mathrm{~m})$ are shown in Figures 6 and 7 , and dust concentration along the pedestrian breathing-height $(\mathrm{X}=5 \mathrm{~m}, \mathrm{Y}=1.5 \mathrm{~m})$ and 


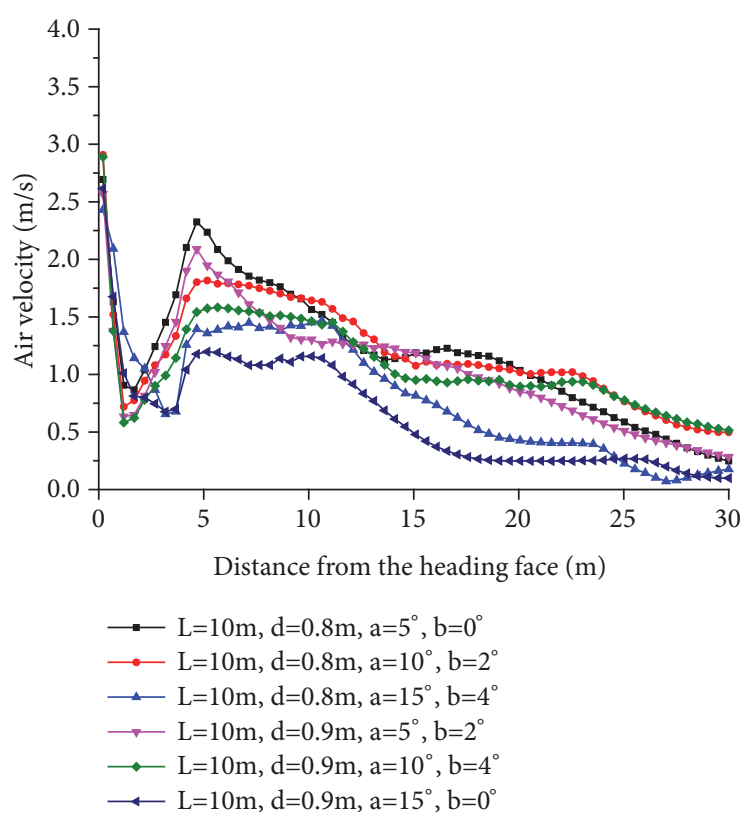

(a)

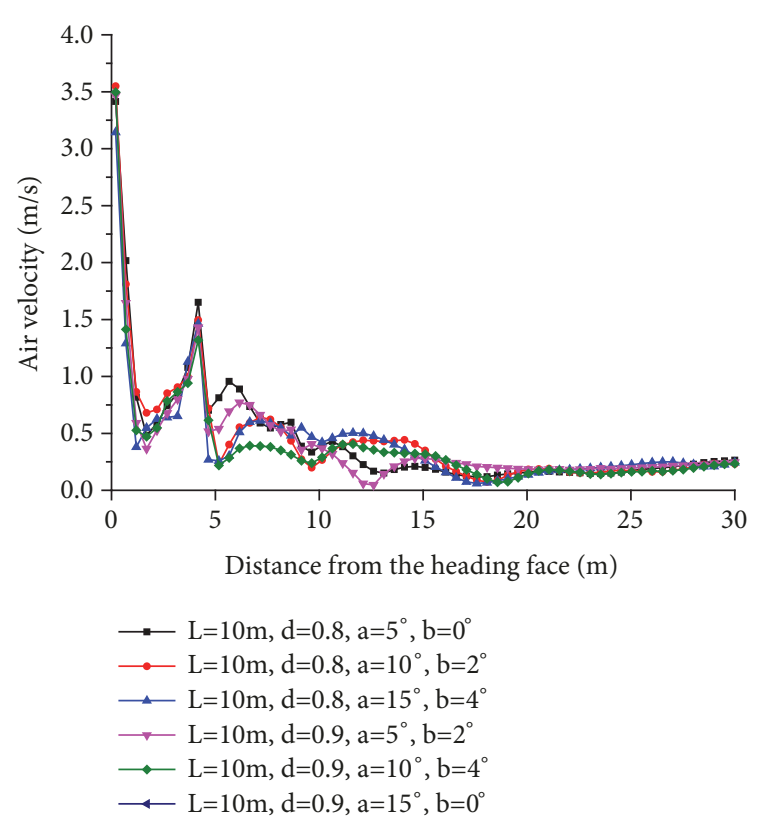

(b)

FIGURE 5: Comparison of air velocity at the farthest distance of $10 \mathrm{~m}$. (a) Air velocity along the pedestrian breathing-height. (b) Air velocity along the driver's breathing-height.

the driver's breathing-height $(\mathrm{X}=3.05 \mathrm{~m}, \mathrm{Y}=2 \mathrm{~m})$ are shown in Figures 8 and 9 .

It can be seen from Figures 6 and 8 that, at the nearest distance of $5 \mathrm{~m}$, the secondary blowing dust easily occurs due to the high air velocity at the outlet. At the caliber of $1.1 \mathrm{~m}$, horizontal right deviation of $10^{\circ}$, and vertical upward deflection of $6^{\circ}$, dust concentration is obviously decreased. Significantly, dust concentration at the pedestrian breathingheight in the backflow side is decreased by $30 \%$ compared with the original field, and dust concentration at the driver location is decreased by $35 \%$ compared with the original one. From Figures 7 and 9, it can be seen that, at the farthest distance of $10 \mathrm{~m}$, the outlet parameters on caliber of $0.9 \mathrm{~m}$, horizontal right deviation of $15^{\circ}$, and vertical upward deflection of $0^{\circ}$, there is a great influence on the overall dust concentration. Respectively, dust concentration at the pedestrian breathing-height is reduced by $38 \%$, and dust concentration at the driver location is reduced by $27 \%$, compared with the results in the original dust field.

In order to meet the more stringent requirements in safety, high efficiency, and environmental protection, it is necessary to analyze dust concentration distribution under the change of the airflow state, so as to dynamically control the airflow for optimizing the distribution of airflow and dust migration in the heading face, thereby improving the underground working environment. Besides, predicting dust concentration in the roadway is also significant, and thus grasping dust concentration at the key position. Through the analysis of the distribution law of dust concentration under airflow adjustment, the factors that have a great influence on dust concentration are determined, specifically the distance from the duct outlet to heading face, the duct outlet caliber, the horizontal right deviation, and the vertical upward deflection, which lays a foundation for the establishment of the dust concentration prediction model under the control of airflow.

\subsection{Prediction Model of Dust Concentration under Airflow Adjustment}

3.2.1. Design of BP Prediction Model Structure. The BP neural network generally consists of three-layer structure, namely, the input layer, the hidden layer, and the output layer. Each neuron is connected to all neurons in the next layer, and there is no connection between neurons in the same layer [25].

The factors affecting dust concentration of the heading face are extremely complicated, including the coal seam and the mining technology. Besides, there is a complex nonlinear relationship between dust concentration and various influencing factors. The analytic hierarchy process (AHP) method is used to analyze the key factors affecting dust concentration in the heading face. The hierarchy general ranking is shown in Table 6.

From Table 6, it can be found that the distance from the duct outlet to heading face, the duct outlet caliber, the horizontal right deviation, the vertical upward deflection, the air velocity at the duct outlet, and dust production play a main role in the dust concentration distribution of roadway; then, we take them as input layer parameters of BP neural network prediction model.

The main hazard caused by dust is impact on the health of the underground workers. Considering the location that has 


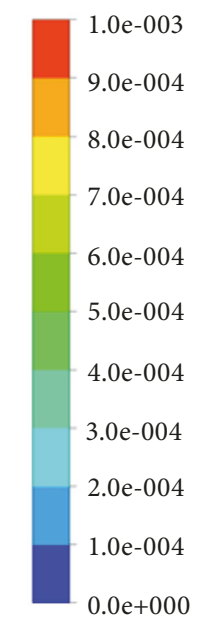

$\left[\mathrm{kg} \mathrm{m}^{\wedge}-3\right]$
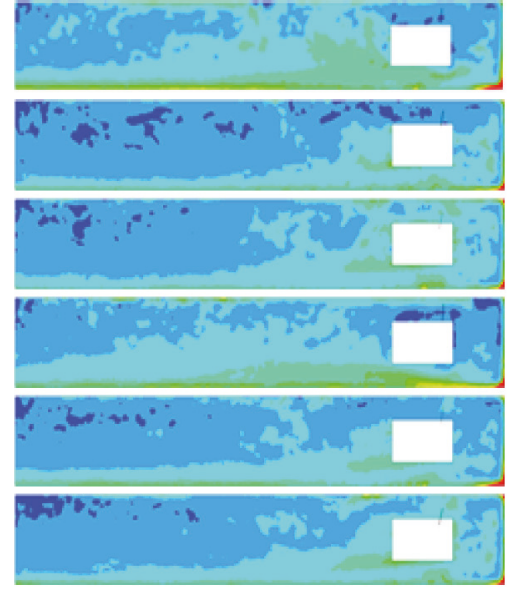

At pedestrian breathing-height area
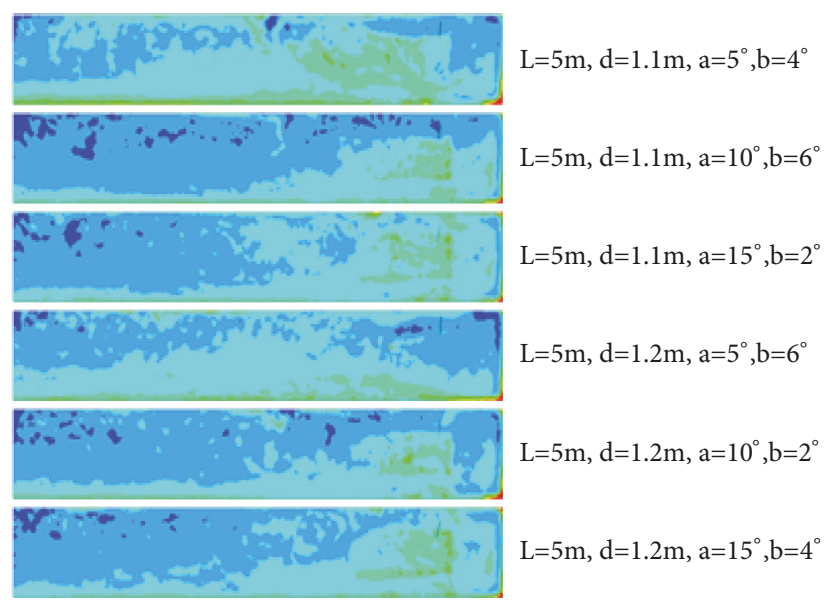

At driver's breathing-height area

Figure 6: Contours of dust concentration under different adjustment schemes at the nearest distance of $5 \mathrm{~m}$.

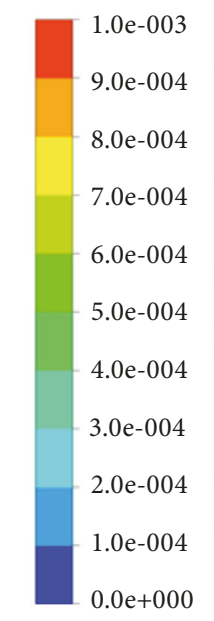

$\left[\mathrm{kg} \mathrm{m}^{\wedge}-3\right]$
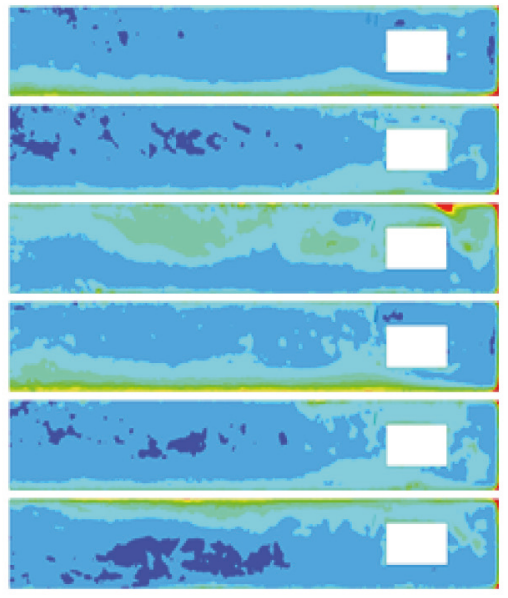

At pedestrian breathing-height area

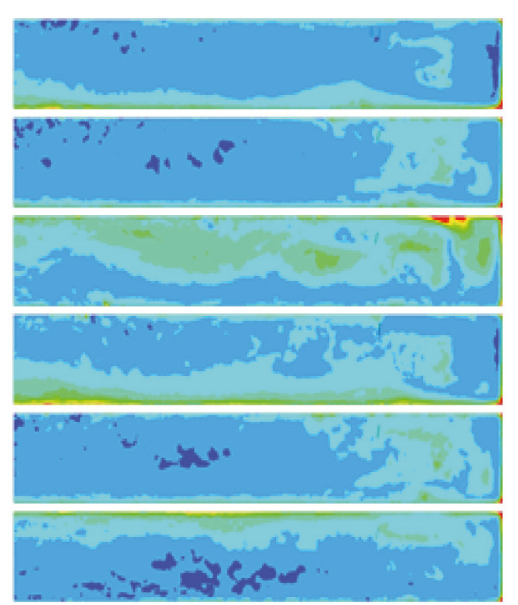

At driver's breathing-height area
$\mathrm{L}=10 \mathrm{~m}, \mathrm{~d}=0.8 \mathrm{~m}, \mathrm{a}=5^{\circ}, \mathrm{b}=0^{\circ}$

$\mathrm{L}=10 \mathrm{~m}, \mathrm{~d}=0.8 \mathrm{~m}, \mathrm{a}=10^{\circ}, \mathrm{b}=2^{\circ}$

$\mathrm{L}=10 \mathrm{~m}, \mathrm{~d}=0.8 \mathrm{~m}, \mathrm{a}=15^{\circ}, \mathrm{b}=4^{\circ}$

$\mathrm{L}=10 \mathrm{~m}, \mathrm{~d}=0.9 \mathrm{~m}, \mathrm{a}=5^{\circ}, \mathrm{b}=2^{\circ}$

$\mathrm{L}=10 \mathrm{~m}, \mathrm{~d}=0.9 \mathrm{~m}, \mathrm{a}=10^{\circ}, \mathrm{b}=4^{\circ}$

$\mathrm{L}=10 \mathrm{~m}, \mathrm{~d}=0.9 \mathrm{~m}, \mathrm{a}=15^{\circ}, \mathrm{b}=0^{\circ}$

Figure 7: Contours of dust concentration under different adjustment schemes at the farthest distance of $10 \mathrm{~m}$.

the greatest impact on the workers which is the breathingheight area, the dust safety hazard and pollution risks comprehensive prediction neural network model under airflow adjustment are established. Thus, the number of nodes in the output layer is 2 , including both dust concentration at the driver location and dust concentration at the pedestrian breathing-height in the backflow side.

The determination of the number of nodes in hidden layer is a difficult problem, and the method affects the prediction results and the complexity of the neural network. Equation (6) is commonly used to calculate the neurons number of the hidden layers.

$$
m=\sqrt{n+l}+a
$$

where $m$ is the number of nodes in hidden layer, $n$ is the number of nodes in input layer, $l$ is the number of nodes in output layer, and $a$ is the constant between 1 and 10 .
Using empirical equation and MATLAB software program, a network with variable number of hidden layer nodes is designed, and the optimal number of nodes is determined by error comparison. The results of MATLAB operation are shown in Table 7.

It can be seen from Table 7 that, under the premise that the number of nodes in hidden layer is 5 , the network error is $1.81 \mathrm{e}-2$, which is the minimum. Thus, the number of nodes in the hidden layer is determined as 5 , and the topology of the network model is 6-5-2. The specific structure is shown in Figure 10.

3.2.2. Data Sample and Preprocessing. Considering the simulation results of the airflow and dust field under the comprehensive changes of influencing factors, dust concentration at the pedestrian breathing-height in the backflow side is the average at three points of $Z=7 \mathrm{~m}, Z=10 \mathrm{~m}$, and $Z=15 \mathrm{~m}$ on the blue line $(X=5 \mathrm{~m}, \mathrm{Y}=1.5 \mathrm{~m}$, and $\mathrm{Z}=0 \sim 40 \mathrm{~m})$, and dust 


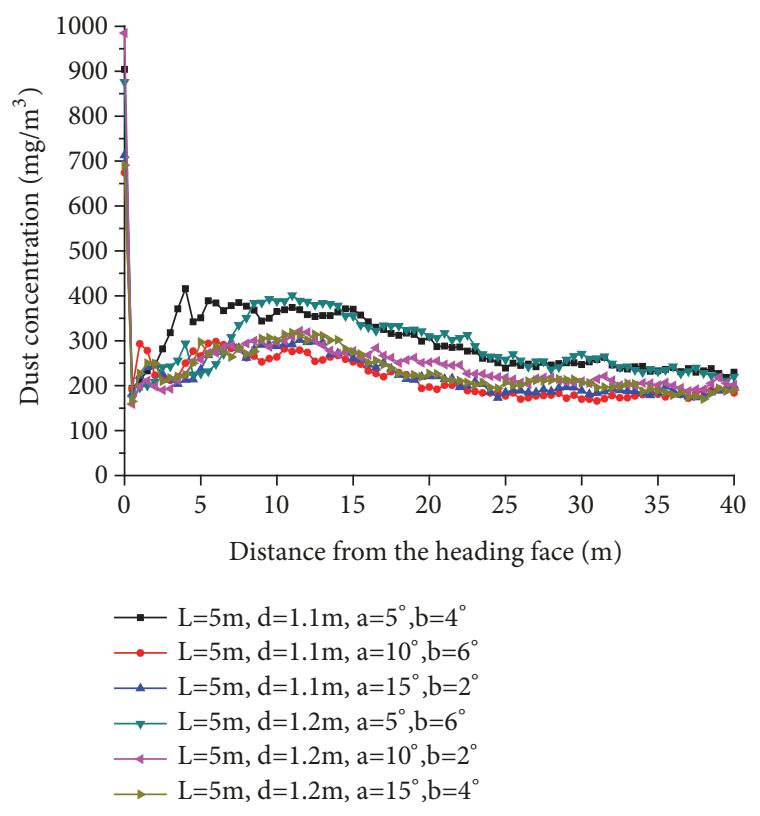

(a)

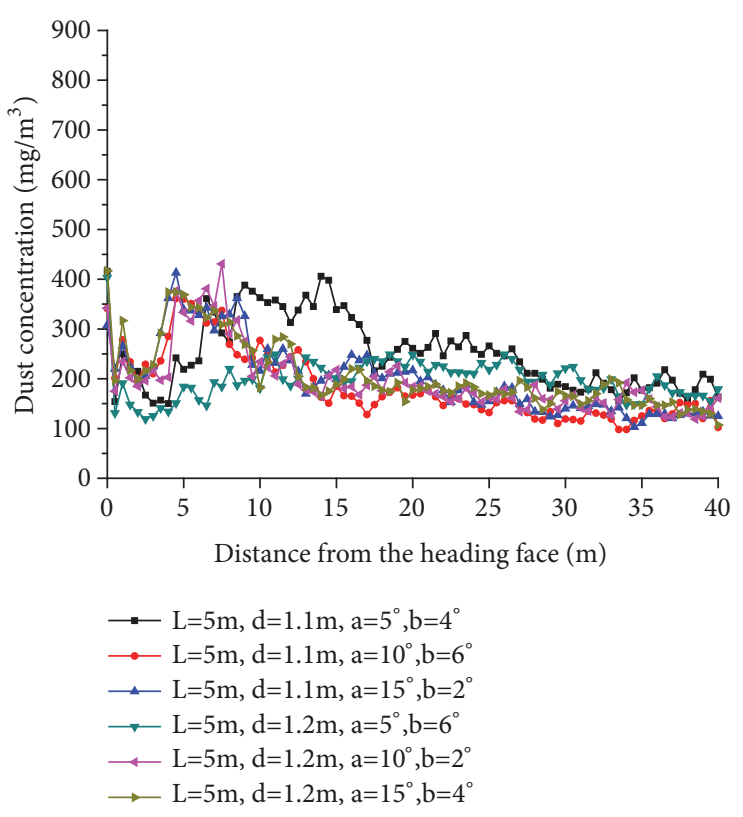

(b)

Figure 8: Comparison of dust concentration at the nearest distance of $5 \mathrm{~m}$. (a) Dust concentration along the pedestrian breathing-height. (b) Dust concentration along the driver's breathing-height.

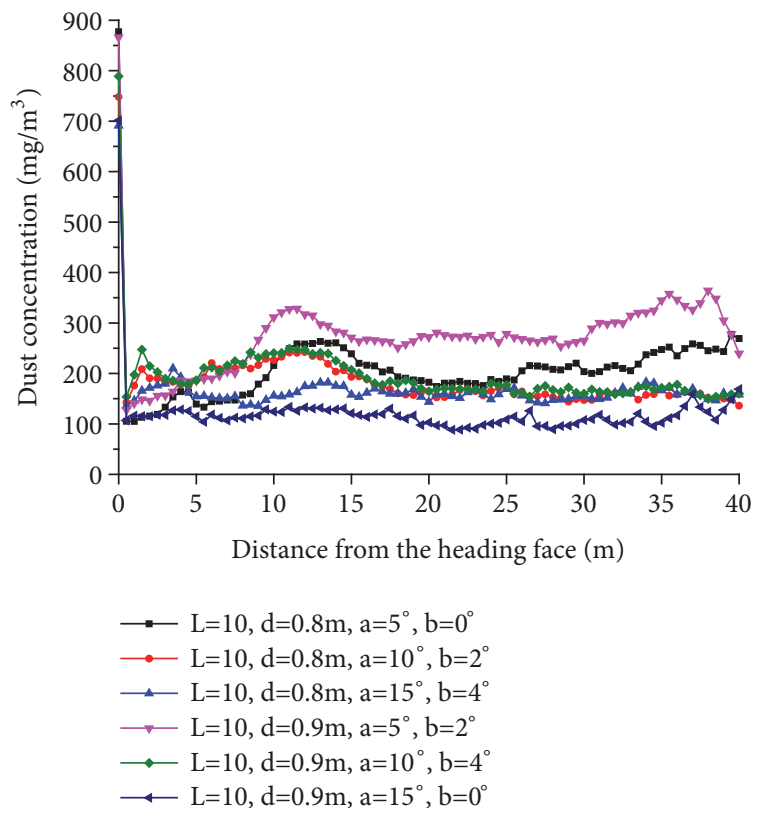

(a)

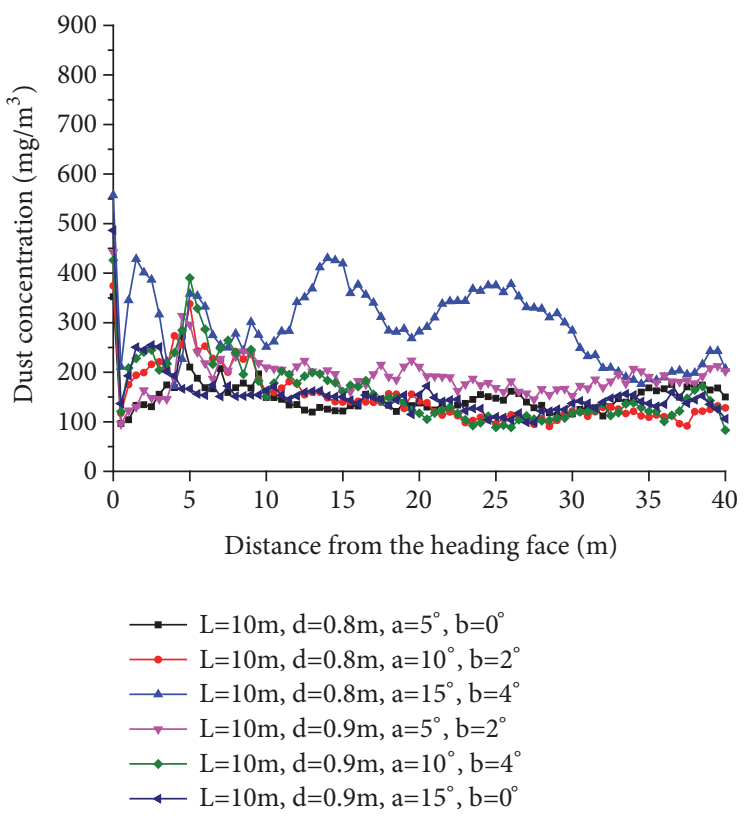

(b)

FIGURE 9: Comparison of dust concentration at the farthest distance of 10m. (a) Dust concentration along the pedestrian breathing-height. (b) Dust concentration along the driver's breathing-height.

concentration at the driver location is the value of the point $(\mathrm{X}=3.05 \mathrm{~m}, \mathrm{Y}=2 \mathrm{~m}$, and $\mathrm{Z}=7.5 \mathrm{~m})$. According to the air velocity between 0.25 and $4 \mathrm{~m} / \mathrm{s}$ specified by The Coal Mine Safety Regulations [24], sample data preprocessing is performed to eliminate unreasonable adjustment schemes. Therefore, the input and output data are obtained (see Tables 8 and 9). The maximum value is 586.11, and the minimum value is 0.0076 .

In order to facilitate the analysis and the network convergence, the data is normalized by (7). The normalized data 
TABLE 6: The hierarchy general ranking.

\begin{tabular}{lcccc}
\hline Rule hierarchy & Weights & Factor hierarchy & Weights & Total sequencing weight \\
\hline & & Distance from the duct outlet to heading face & 0.4673 & 0.292 \\
Adjustment parameters & 0.6250 & Caliber of the duct outlet & 0.2772 & 0.173 \\
& & Horizontal right deviation & 0.1601 & 0.0954 \\
& & Vertical upward deflection & 0.5715 & 0.060 \\
Original gas and dust parameters & 0.3285 & Gas emission quantity & 0.2857 & 0.186 \\
& & Dust production & 0.1428 & 0.75 \\
Ventilation parameters & \multirow{2}{*}{0.1365} & Particle size & 0.047 & 0.102 \\
& & Air velocity at the duct outlet & 0.034 \\
\hline
\end{tabular}

TABLE 7: Error under the different number of nodes in hidden layer.

\begin{tabular}{lccccc}
\hline The number of nodes & Error & Iteration times & The number of nodes & Error & Iteration times \\
\hline 4 & $5.76 \mathrm{e}-2$ & 7 & 9 & 10 & $4.20 \mathrm{e}-2$ \\
5 & $1.81 \mathrm{e}-2$ & 16 & 11 & $61 \mathrm{e}-1$ & $6.85 \mathrm{e}-2$ \\
6 & $1.14 \mathrm{e}-1$ & 8 & 12 & $5.58 \mathrm{e}-2$ & 18 \\
7 & $6.60 \mathrm{e}-2$ & 6 & 13 & $3.11 \mathrm{e}-2$ & 14 \\
8 & $6.13 \mathrm{e}-2$ & 18 & & 12 \\
\hline
\end{tabular}

are used as training and testing data for the BP prediction model.

$$
\hat{x}_{i}=\frac{x_{i}-x_{\min }}{x_{\max }-x_{\min }}
$$

where $x_{i}$ is the input or output data, $x_{\max }$ is the maximum value, and $x_{\text {min }}$ is the minimum value.

\subsubsection{Determining Functions of Neural Network. Combined} with the sample data in Tables 8 and 9, the transfer, training, and learning functions are used to train the double-objective BP prediction model. According to the mean square error and iteration times, the most suitable transfer function, training function, and learning function are selected. The comparison results of different functions are shown in Table 10.

Under the premise that the mean square error is the minimum, the function with the smallest iteration times is selected. For the double-objective prediction model of dust concentration under airflow adjustment, the transfer function is logsig, the training function is trainlm, and the learning function is learngd.

\subsubsection{Double-Objective Prediction Model of Dust Concentra-} tion under Airflow Adjustment. The number of input nodes at double-objective prediction model is 6 , including the distance from the duct outlet to heading face, the duct outlet caliber, the horizontal right deviation, the vertical upward deflection, the air velocity at the duct outlet, and dust production. The number of nodes in hidden layer is 5 , and the number of output nodes is 2 , involving dust concentration at the driver location and dust concentration at the pedestrian breathing-height in the backflow side. The transfer function is logsig, the training function is trainlm, and the learning function is learngd. According to the designed double-objective prediction model, the top 74 data is trained by using the neural network toolbox. The max training times for the network is set as 1000 and the learning rate is 0.5 . The training results are shown in Figure 11.

It can be seen from Figure 11(a) that the network training has reached the accuracy requirement after 13 iterations, and the number of verification steps is 6 . From Figure 11(b), it can be seen that the network model needs 13 training steps to achieve convergence, and the mean square error is 0.015532 . The prediction model of dust concentration under airflow adjustment is trained by using BP neural network, the mean square error is minimal, and the network tends to be stable. From Figure 11(c), it can be seen that the network training is ended when the gradient approaches 0.01 ; the value of mu determines whether the learning is done according to the Newton method or the gradient method; val fail is the maximum number of verification failures. When the error is tested at 6 times, the error does not decrease or rise, indicating that the training set error is no longer decreased, and the network stops training.

The weights between nodes in different layers are shown in Tables 11 and 12, and thresholds of hidden layer nodes are shown in Table 13.

In addition, the thresholds of the output layer nodes are 0.82971 and 1.2618 .

The latter 10 data in Tables 8 and 9 is used as test sample to examine the effect of the dust concentration prediction model under the airflow adjustment. The comparison between test values and predicted values is shown in Table 14. It can be seen that the maximum relative error is $9.11 \%$, and the minimum value is $0.74 \%$. The prediction model has high precision and meets the requirements; therefore, it can accurately predict dust concentration at the pedestrian breathing-height and driver location under airflow adjustment. 


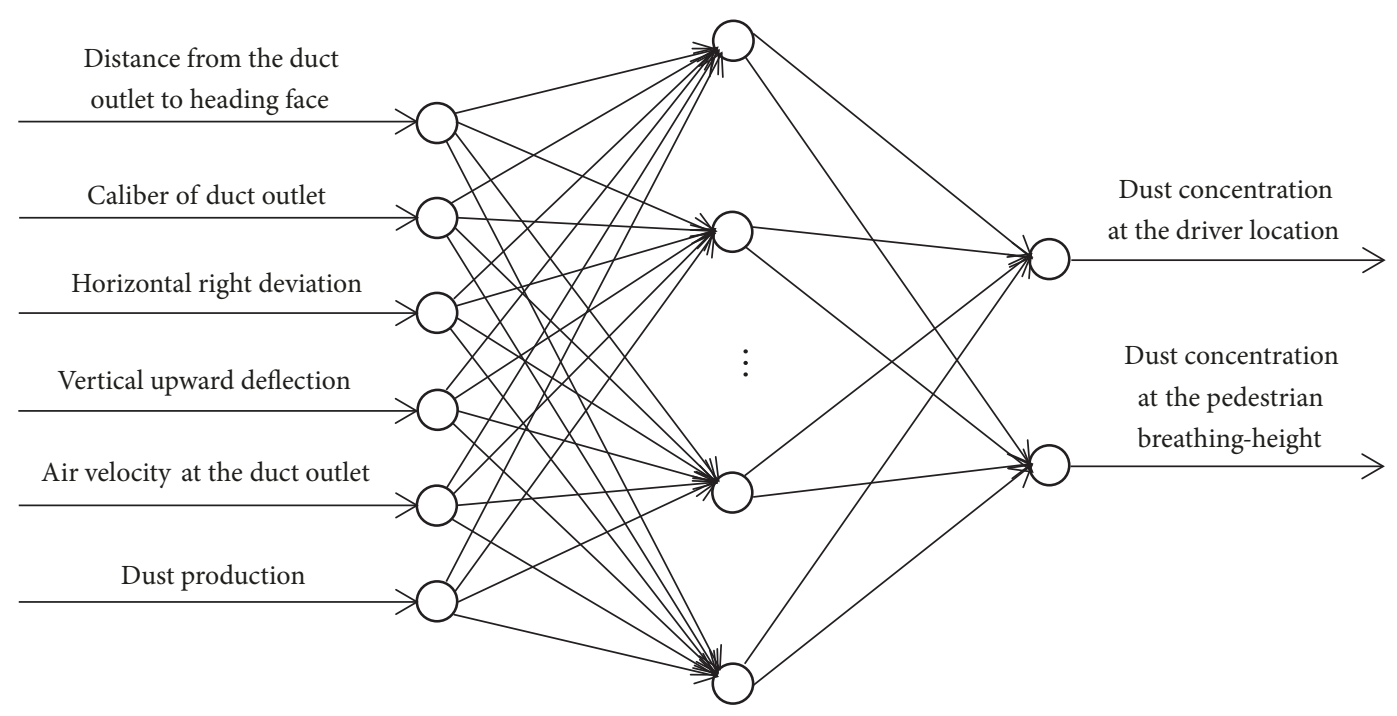

FIGURE 10: The network model structure of dust concentration prediction.

\section{Discussion}

4.1. Analysis on Practical Application. Taking Ningtiaota coal mine in Northern Shaanxi province of China as the research object, the analysis of dust concentration prediction and optimal adjustment scheme are carried out. At the nearest distance of $5 \mathrm{~m}$ and the farthest distance of $10 \mathrm{~m}$ from the duct outlet to heading face, the adjustment schemes are established, and the BP prediction model is used to predict dust concentration under different adjustment schemes. By analyzing and comparing the minimum value, the optimal adjustment scheme of the best dust removal effect is obtained.

At the nearest distance of $5 \mathrm{~m}$ from the duct outlet to heading face, the effective range of the jet region is large, resulting in high air velocity at the end of the jet, and air velocity at the outlet is reduced by increasing the caliber of duct outlet. Therefore, the duct outlet caliber is $1.1 \mathrm{~m}$ or $1.2 \mathrm{~m}$, the horizontal right deviation is $5 \sim 25^{\circ}$, and the vertical upward deflection is $2 \sim 6^{\circ}$. The airflow adjustment schemes at the nearest distance of $5 \mathrm{~m}$ are shown in Table 15 .

According to the practical investigation in Ningtiaota coal mine, the dust production is $0.0096 \mathrm{~kg} / \mathrm{s}$, air velocity at the outlet is $5.94 \mathrm{~m} / \mathrm{s}$ when the caliber is $1.1 \mathrm{~m}$, and air velocity at the outlet is $5.27 \mathrm{~m} / \mathrm{s}$ when the caliber is $1.2 \mathrm{~m}$. The established BP prediction model is used to predict dust concentration of 30 schemes; thus, the dust concentration at the pedestrian breathing-height and driver location is obtained (see Table 16).

According to scheme 9 from Table 16, the optimal adjustment scheme at the nearest distance of $5 \mathrm{~m}$ is obtained. Dust concentration at the driver location is $325.36 \mathrm{mg} / \mathrm{m}^{3}$ after the adjustment of scheme 9, and dust concentration at the pedestrian breathing-height is $304.32 \mathrm{mg} / \mathrm{m}^{3}$, which all reach the minimum relatively. And the corresponding distance is $5 \mathrm{~m}$ from the duct outlet to heading face, the caliber is $1.1 \mathrm{~m}$, the horizontal right deviation is $15^{\circ}$, and the vertical upward deflection is $6^{\circ}$. The dust concentration is compared with that before adjustment (see Table 17).
At the farthest distance of $10 \mathrm{~m}$ from the duct outlet to heading face, the established neural network model is used to predict dust concentration under different schemes, and the optimal adjustment scheme is obtained. After adjustment, dust concentration at the driver location is 376.09 $\mathrm{mg} / \mathrm{m}^{3}$, which is decreased by $35 \%$, and dust concentration at the pedestrian breathing-height is $323.49 \mathrm{mg} / \mathrm{m}^{3}$, which is decreased by $33 \%$. The corresponding distance is $10 \mathrm{~m}$ from the duct outlet to heading face, the caliber is $0.8 \mathrm{~m}$, the horizontal right deviation is $15^{\circ}$, and the vertical upward deflection is $2^{\circ}$.

4.2. Underground Test Verification. We have developed the duct outlet control device and carried out the underground actual tests in Ningtiaota coal mine last year. The main hazard of dust in the heading face is reflected in the impact on the health of underground workers. Considering the location that has the greatest impact on workers, which is breathingheight area, dust concentration at the driver location and pedestrian breathing-height in the backflow side is selected as the test objects. The underground measuring points are shown in Figure 12.

(1) Underground Test at the Nearest Distance of $5 \mathrm{~m}$. According to the arrangement of underground measuring points in Figure 12, the original dust concentration measured data is obtained at the nearest distance of $5 \mathrm{~m}$ (see Table 18). Taking the optimal adjustment scheme obtained by the prediction model as the underground test scheme, the measured data is shown in Table 19. Then, dust concentration before and after adjustment is compared (see Figure 13).

From Tables 18 and 19 and Figure 13, it can be seen that the dust removal effect is obvious after adjustment. Dust concentration at the driver location is decreased by $34 \%$, and dust concentration at the pedestrian breathing-height in the backflow side is decreased by $29 \%$ compared with that before adjustment. 


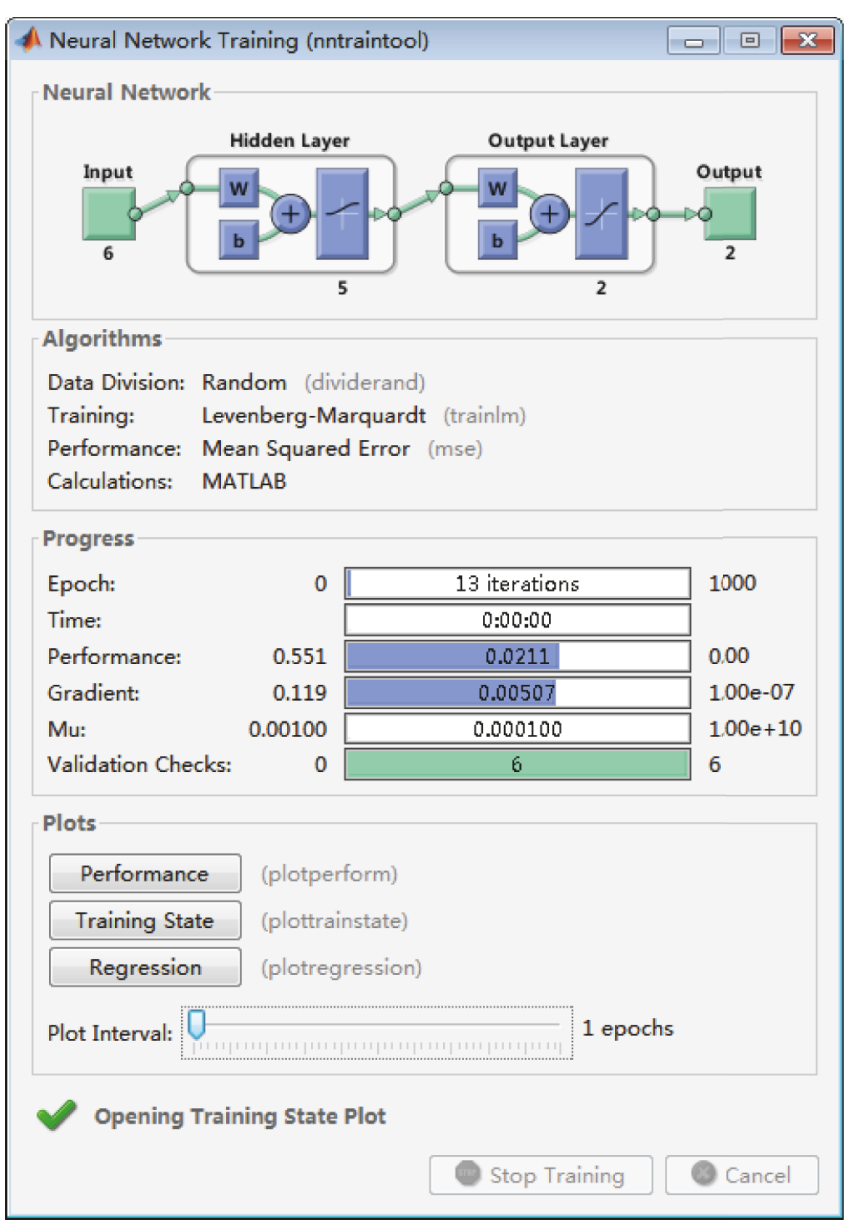

(a)

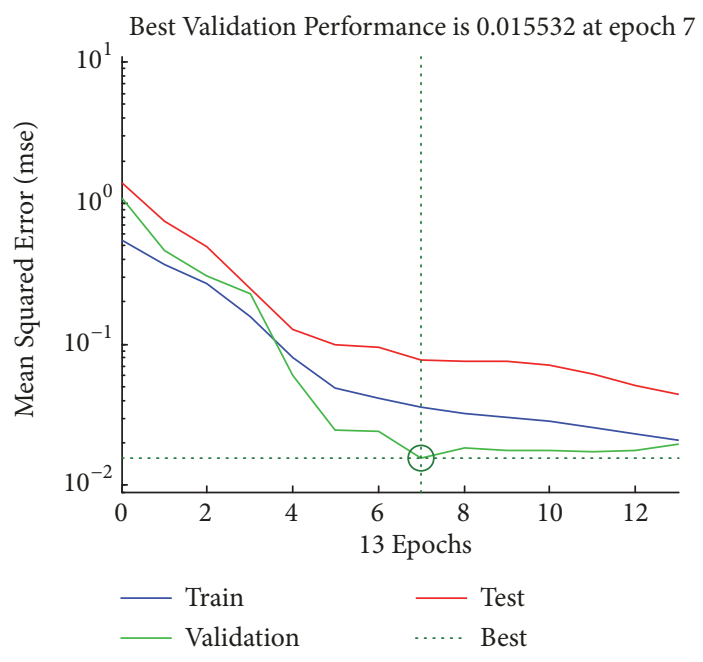

(b)

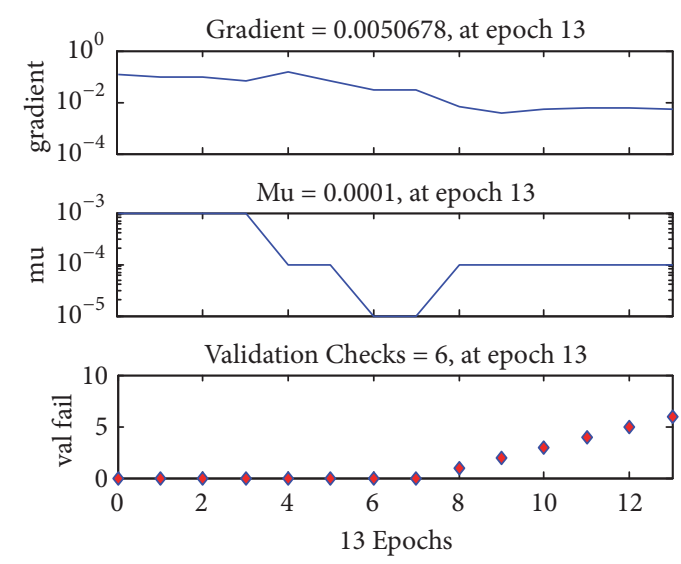

(c)

FIgURE 11: Training results of dust concentration prediction model. (a) Training interface. (b) Mean squared error. (c) Training state.

(2) Underground Test at the Farthest Distance of $10 \mathrm{~m}$. According to the underground measuring points in Figure 12, the original dust concentration measured data are obtained at the farthest distance of $10 \mathrm{~m}$ (see Table 20). Taking the optimal adjustment scheme obtained by the prediction model as the underground test scheme, the measured data are shown in
Table 21, and dust concentration before and after adjustment is compared (see Figure 14).

It can be seen from Tables 20 and 21 and Figure 14 that dust concentration at the driver location is decreased by $33 \%$, and dust concentration at the pedestrian breathing-height in the backflow side is decreased by $31 \%$. 
TABLE 8: The input layer data.

\begin{tabular}{|c|c|c|c|c|c|c|}
\hline Number & Distance (m) & Caliber (m) & $\begin{array}{c}\text { Horizontal right } \\
\text { deviation }\left({ }^{\circ}\right)\end{array}$ & $\begin{array}{c}\text { Vertical upward } \\
\text { deflection }\left({ }^{\circ}\right)\end{array}$ & $\begin{array}{c}\text { Air velocity } \\
(\mathrm{m} / \mathrm{s})\end{array}$ & $\begin{array}{l}\text { Dust production } \\
(\mathrm{kg} / \mathrm{s})\end{array}$ \\
\hline 1 & 5 & 1.1 & 5 & 2 & 5.43 & 0.0076 \\
\hline 2 & 5 & 1.1 & 5 & 6 & 5.68 & 0.0076 \\
\hline 3 & 5 & 1.1 & 15 & 2 & 5.17 & 0.0076 \\
\hline 4 & 5 & 1.1 & 15 & 6 & 5.31 & 0.0076 \\
\hline 5 & 5 & 1.2 & 5 & 6 & 4.82 & 0.0076 \\
\hline 6 & 5 & 1.2 & 15 & 2 & 5.27 & 0.0076 \\
\hline 7 & 5 & 1.2 & 25 & 2 & 5.19 & 0.0076 \\
\hline 8 & 5 & 1.2 & 5 & 2 & 4.98 & 0.0076 \\
\hline 9 & 6 & 1 & 5 & 6 & 5.61 & 0.0076 \\
\hline$\vdots$ & $\vdots$ & $\vdots$ & $\vdots$ & $\vdots$ & $\vdots$ & $\vdots$ \\
\hline 76 & 9 & 0.9 & 25 & 6 & 6.51 & 0.0116 \\
\hline 77 & 10 & 0.7 & 5 & 2 & 6.81 & 0.0116 \\
\hline 78 & 10 & 0.7 & 15 & 6 & 6.94 & 0.0116 \\
\hline 79 & 10 & 0.7 & 25 & 6 & 6.87 & 0.0116 \\
\hline 80 & 10 & 0.7 & 15 & 2 & 7.04 & 0.0116 \\
\hline 81 & 10 & 0.8 & 5 & 2 & 6.51 & 0.0116 \\
\hline 82 & 10 & 0.8 & 15 & 6 & 6.43 & 0.0116 \\
\hline 83 & 10 & 0.8 & 25 & 6 & 6.72 & 0.0116 \\
\hline 84 & 10 & 0.8 & 15 & 2 & 6.86 & 0.0116 \\
\hline
\end{tabular}

Table 9: The output layer data.

\begin{tabular}{|c|c|c|}
\hline Number & $\begin{array}{l}\text { Dust concentration at the } \\
\text { driver location }\left(\mathrm{mg} / \mathrm{m}^{3}\right)\end{array}$ & $\begin{array}{c}\text { Dust concentration at the pedestrian } \\
\text { breathing-height }\left(\mathrm{mg} / \mathrm{m}^{3}\right)\end{array}$ \\
\hline 1 & 293.40 & 280.45 \\
\hline 2 & 307.82 & 294.34 \\
\hline 3 & 274.41 & 286.35 \\
\hline 4 & 220.64 & 270.35 \\
\hline 5 & 326.64 & 243.83 \\
\hline 6 & 283.89 & 304.80 \\
\hline 7 & 331.24 & 318.07 \\
\hline 8 & 322.52 & 237.90 \\
\hline 9 & 319.91 & 221.07 \\
\hline$\vdots$ & $\vdots$ & $\vdots$ \\
\hline 76 & 508.42 & 532.20 \\
\hline 77 & 462.64 & 528.20 \\
\hline 78 & 461.91 & 491.39 \\
\hline 79 & 403.29 & 487.09 \\
\hline 80 & 447.94 & 507.06 \\
\hline 81 & 445.01 & 516.14 \\
\hline 82 & 454.15 & 478.11 \\
\hline 83 & 499.62 & 483.24 \\
\hline 84 & 452.98 & 507.23 \\
\hline
\end{tabular}

\section{Conclusions}

Based on the airflow and dust field numerical simulation analysis and the large amount of sample data under the change of airflow adjustment parameters, the doubleobjective BP prediction model of dust concentration is established for the safety hazard in the backflow side and the pollution risks at driver location. The distribution law and 
TABLE 10: The comparison results of different functions.

\begin{tabular}{lccc}
\hline Function type & Function name & Iteration times & Mean square error \\
\hline \multirow{3}{*}{ Transfer function } & logsig & 9 & $2.52 \mathrm{e}-2$ \\
& tansig & 11 & $4.65 \mathrm{e}-2$ \\
& purelin & 9 & $6.68 \mathrm{e}-1$ \\
Training function & traingdm & 1000 & $3.17 \mathrm{e}-1$ \\
& trainglm & 11 & $5.57 \mathrm{e}-2$ \\
& traingdx & 137 & $8.52 \mathrm{e}-1$ \\
Learning function & learngdm & 139 & $7.41 \mathrm{e}-2$ \\
& learngd & 25 & $3.46 \mathrm{e}-2$ \\
\hline
\end{tabular}

TABLE 11: The weights from input layer nodes to hidden layer nodes.

\begin{tabular}{lcccccc}
\hline Input layer nodes & $\mathrm{X} 1$ & $\mathrm{X} 2$ & $\mathrm{X} 3$ & $\mathrm{X} 4$ & $\mathrm{X} 5$ & -2.5342 \\
\hline & 2.4314 & -0.0622 & -1.2612 & 1.0935 & -0.7830 & -0.7608 \\
Hidden layer nodes & 1.3383 & -1.0115 & 2.0125 & -0.5057 \\
& -0.5912 & -1.0331 & -0.2196 & -0.5322 & -1.4287 & -0.0306 \\
& 2.8285 & -4.8427 & 0.0719 & 0.2652 & -1.9597 \\
& 0.6135 & -1.1564 & 0.4116 & & -0.3303 \\
\hline
\end{tabular}

TABLE 12: The weights from hidden layer nodes to output layer nodes.

\begin{tabular}{lccccc}
\hline Hidden layer nodes & 1 & 2 & 3 & 4 & 5 \\
\hline \multirow{2}{*}{ Output layer nodes } & 2.2022 & -0.4141 & -2.1345 & -0.7098 & 0.9605 \\
& -0.3397 & -0.3385 & -1.9866 & -0.4598 & -1.0131 \\
\hline
\end{tabular}

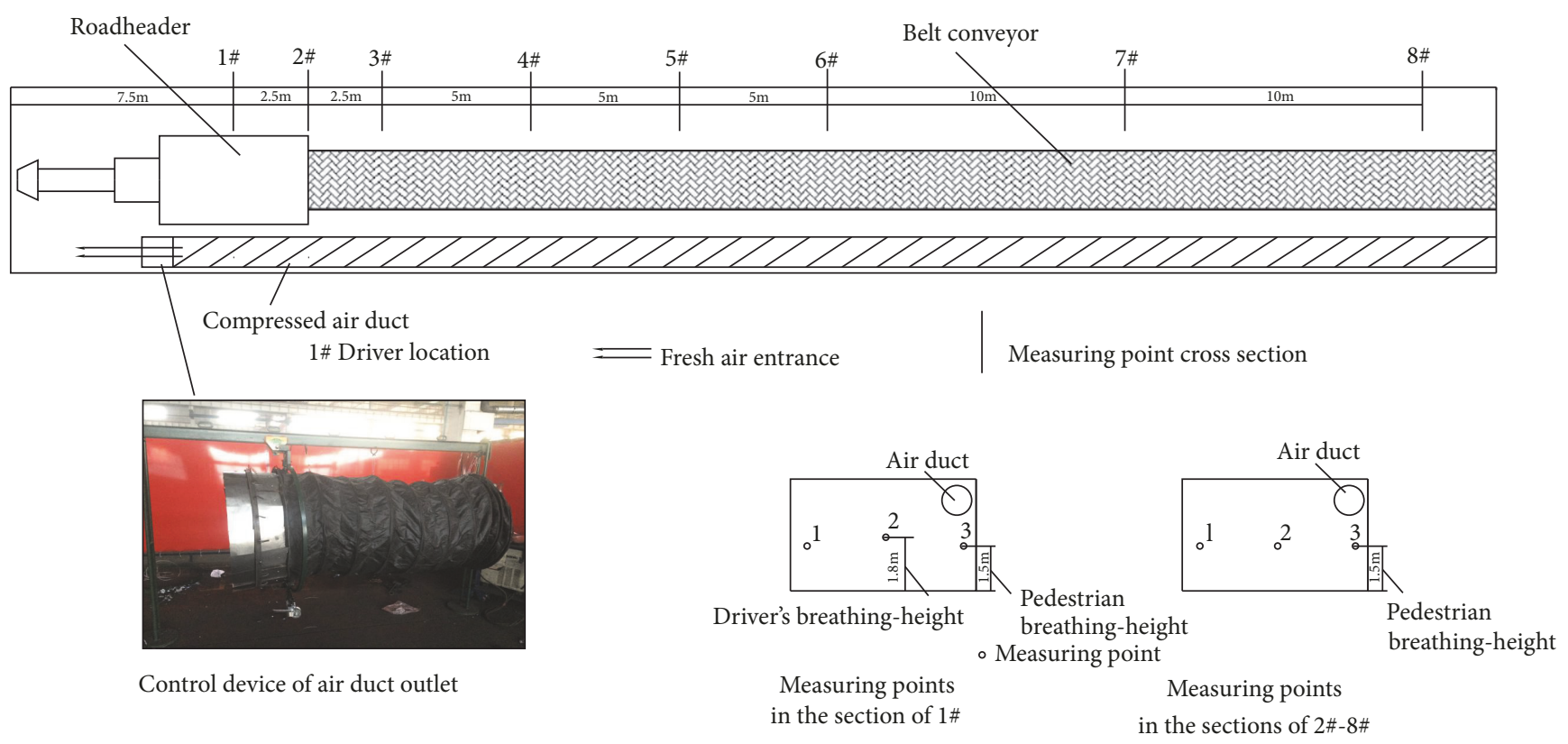

FIGURE 12: Arrangement of underground measuring points.

TABLE 13: Thresholds of hidden layer nodes.

\begin{tabular}{lccccc}
\hline Hidden layer nodes & 1 & 2 & 3 & 4 & 5 \\
\hline Thresholds & -4.2854 & -3.2851 & 0.4871 & 0.3751 & -4.8327 \\
\hline
\end{tabular}

prediction model of dust concentration under airflow adjustment are verified in S1212 of Ningtiaota coal mine through the self-developed control device. The specific conclusions are as follows. 
TABLE 14: The comparison between test value and predicted value.

\begin{tabular}{|c|c|c|c|c|c|c|c|}
\hline \multirow{2}{*}{$\begin{array}{l}\text { Test value at the } \\
\text { driver location } \\
\left(\mathrm{mg} / \mathrm{m}^{3}\right)\end{array}$} & \multirow{2}{*}{ 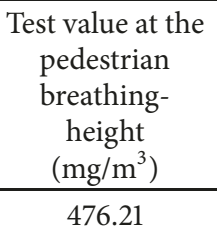 } & \multirow{2}{*}{$\begin{array}{l}\begin{array}{c}\text { Predicted value } \\
\text { at the driver } \\
\text { location } \\
\left(\mathrm{mg} / \mathrm{m}^{3}\right)\end{array} \\
480.74\end{array}$} & \multirow{2}{*}{$\begin{array}{c}\text { Predicted value } \\
\text { at the pedestrian } \\
\begin{array}{c}\text { breathing- } \\
\text { height } \\
\left(\mathrm{mg} / \mathrm{m}^{3}\right)\end{array} \\
508.49\end{array}$} & \multicolumn{2}{|c|}{ Absolute error } & \multicolumn{2}{|c|}{ Relative error (\%) } \\
\hline & & & & 25.39 & 32.28 & 5.58 & 6.78 \\
\hline 508.42 & 532.20 & 512.19 & 483.70 & 3.77 & 48.50 & 0.74 & 9.11 \\
\hline 462.64 & 528.20 & 483.55 & 533.60 & 20.91 & 5.40 & 4.52 & 1.02 \\
\hline 461.91 & 491.39 & 449.80 & 515.04 & 12.11 & 23.65 & 2.62 & 4.81 \\
\hline 403.29 & 487.09 & 415.54 & 481.65 & 12.25 & 5.44 & 3.04 & 1.12 \\
\hline 447.94 & 507.06 & 452.53 & 523.94 & 4.59 & 16.88 & 1.02 & 3.33 \\
\hline 445.01 & 516.14 & 468.57 & 521.58 & 23.56 & 5.44 & 5.29 & 1.05 \\
\hline 454.15 & 478.11 & 467.89 & 493.32 & 13.74 & 15.21 & 3.03 & 3.18 \\
\hline 499.62 & 483.24 & 475.09 & 490.14 & 24.53 & 6.90 & 4.91 & 1.43 \\
\hline 452.98 & 507.23 & 465.85 & 545.50 & 12.87 & 38.27 & 2.84 & 7.54 \\
\hline
\end{tabular}

TABLE 15: The adjustment schemes at the nearest distance of $5 \mathrm{~m}$.

\begin{tabular}{lccc}
\hline Scheme & Caliber $(\mathrm{m})$ & Horizontal right deviation $\left(^{\circ}\right)$ & Vertical upward deflection $\left(^{\circ}\right)$ \\
\hline 1 & 1.1 & 5 & 2 \\
2 & 1.1 & 5 & 4 \\
3 & 1.1 & 5 & 6 \\
4 & 1.1 & 10 & 2 \\
$\vdots$ & $\vdots$ & $\vdots$ & $\vdots$ \\
28 & 1.2 & 25 & 2 \\
29 & 1.2 & 25 & 4 \\
30 & 1.2 & 25 & 6 \\
\hline
\end{tabular}

TABLE 16: Dust concentration under different adjustment schemes at the nearest distance of $5 \mathrm{~m}$.

\begin{tabular}{lcc}
\hline Scheme & $\begin{array}{c}\text { Dust concentration at the } \\
\text { driver location }\left(\mathrm{mg} / \mathrm{m}^{3}\right)\end{array}$ & $\begin{array}{c}\text { Dust concentration at the pedestrian } \\
\text { breathing-height }\left(\mathrm{mg} / \mathrm{m}^{3}\right)\end{array}$ \\
\hline 1 & 329.07 & 342.38 \\
2 & 347.82 & 363.36 \\
3 & 411.41 & 429.07 \\
4 & 375.64 & 363.06 \\
$\vdots$ & $\vdots$ & $\vdots$ \\
28 & 331.76 & 429.29 \\
29 & 334.04 & 409.71 \\
30 & 345.38 & 457.73 \\
\hline
\end{tabular}

(1) The problems of airflow and dust field under the original ventilation mode and the influence of airflow adjustment parameters on the distribution of airflow and dust migration are analyzed. We come to the conclusion of the distribution law of air velocity and dust concentration under various adjustment schemes. At the nearest distance of $5 \mathrm{~m}$, the caliber of duct outlet is $1.1 \mathrm{~m}$ or $1.2 \mathrm{~m}$, the horizontal right deviation is $5 \sim 15^{\circ}$, the vertical upward deflection is $2 \sim 6^{\circ}$, and the airflow and dust field are distributed reasonably. At the farthest distance of $10 \mathrm{~m}$, the caliber of duct outlet is $0.8 \mathrm{~m}$ or $0.9 \mathrm{~m}$, the horizontal right deviation is $5 \sim 15^{\circ}$, and the vertical upward deflection is $0 \sim 4^{\circ}$, the minimum air velocity is higher than the minimum limit of $0.25 \mathrm{~m} / \mathrm{s}$ specified by The Coal Mine Safety Regulations, and the dust field is better distributed.

(2) The input layer parameters of the double-objective prediction model are determined as the distance from the duct outlet to heading face, the duct outlet caliber, the horizontal right deviation, the vertical upward deflection, the air velocity at the duct outlet, and dust production. The optimal number of hidden layer nodes is 5 . And the output layer includes dust concentration at the driver location and the pedestrian breathing-height in the backflow side. The 
TABLE 17: Analysis of adjustment effect at the nearest distance of $5 \mathrm{~m}$.

\begin{tabular}{lcc}
\hline Predictive object & $\begin{array}{c}\text { Dust concentration at the } \\
\text { driver location }\left(\mathrm{mg} / \mathrm{m}^{3}\right)\end{array}$ & $\begin{array}{c}\text { Dust concentration at the pedestrian } \\
\text { breathing-height }\left(\mathrm{mg} / \mathrm{m}^{3}\right)\end{array}$ \\
\hline Before adjustment & 517 & 447 \\
After adjustment & 325.36 & 304.32 \\
Reduced percentage & 37 & 32 \\
\hline
\end{tabular}

TABLE 18: Test results at the nearest distance of $5 \mathrm{~m}$ before adjustment.

\begin{tabular}{llcccccccc}
\hline Measuring object & \multicolumn{10}{c}{ Dust concentration $\left(\mathrm{mg} / \mathrm{m}^{3}\right)$} \\
\hline Test section & & $1 \#$ & $2 \#$ & $3 \#$ & $4 \#$ & $5 \#$ & $6 \#$ & $7 \#$ & $8 \#$ \\
Measuring points & 1 & 486.2 & 431.6 & 364.4 & 321.3 & 284.6 & 256.2 & 239.4 & 205.8 \\
& 2 & 541.1 & 471.5 & 369.6 & 310.8 & 233.1 & 225.8 & 233.1 & 215.3 \\
\hline
\end{tabular}

TABLE 19: Test results at the nearest distance of $5 \mathrm{~m}$ after adjustment.

\begin{tabular}{llcccccccc}
\hline Measuring object & \multicolumn{10}{c}{ Dust concentration $\left(\mathrm{mg} / \mathrm{m}^{3}\right)$} \\
\hline Test section & & $1 \#$ & $2 \#$ & $3 \#$ & $4 \#$ & $5 \#$ & $6 \#$ & $7 \#$ & $8 \#$ \\
Measuring points & 1 & 347.3 & 309.8 & 300.3 & 239.4 & 223.7 & 187.9 & 183.8 & 176.4 \\
& 2 & 357.4 & 322.4 & 189.5 & 203.7 & 177.3 & 145.5 & 126.8 & 115.5 \\
\hline
\end{tabular}

TABLE 20: Test results at the farthest distance of $10 \mathrm{~m}$ before adjustment.

\begin{tabular}{|c|c|c|c|c|c|c|c|c|c|}
\hline \multirow{2}{*}{$\begin{array}{l}\text { Measuring object } \\
\text { Test section }\end{array}$} & & \multicolumn{8}{|c|}{ Dust concentration $\left(\mathrm{mg} / \mathrm{m}^{3}\right)$} \\
\hline & & $1 \#$ & $2 \#$ & $3 \#$ & $4 \#$ & $5 \#$ & $6 \#$ & 7\# & $8 \#$ \\
\hline \multirow{2}{*}{ Measuring points } & 1 & 504.2 & 443.1 & 384.3 & 686.7 & 592.2 & 501.9 & 478.8 & 510.3 \\
\hline & 2 & 590.6 & 436.8 & 396.9 & 499.8 & 558.6 & 661.5 & 575.4 & 537.6 \\
\hline
\end{tabular}

TABLE 21: Test results at the farthest distance of $10 \mathrm{~m}$ after adjustment.

\begin{tabular}{llcccccccc}
\hline Measuring object & 10 & \multicolumn{1}{c}{ Dust concentration $\left(\mathrm{mg} / \mathrm{m}^{3}\right)$} \\
\hline Test section & & $1 \#$ & $2 \#$ & $3 \#$ & $4 \#$ & $5 \#$ & $6 \#$ & $7 \#$ & $8 \#$ \\
\multirow{2}{*}{ Measuring points } & 1 & 346.2 & 291.9 & 323.4 & 354.1 & 256.2 & 278.2 & 255.7 & 265.5 \\
& 2 & 397.8 & 322.1 & 352.8 & 304.5 & 266.7 & 277.2 & 220.5 & 222.6 \\
\hline
\end{tabular}

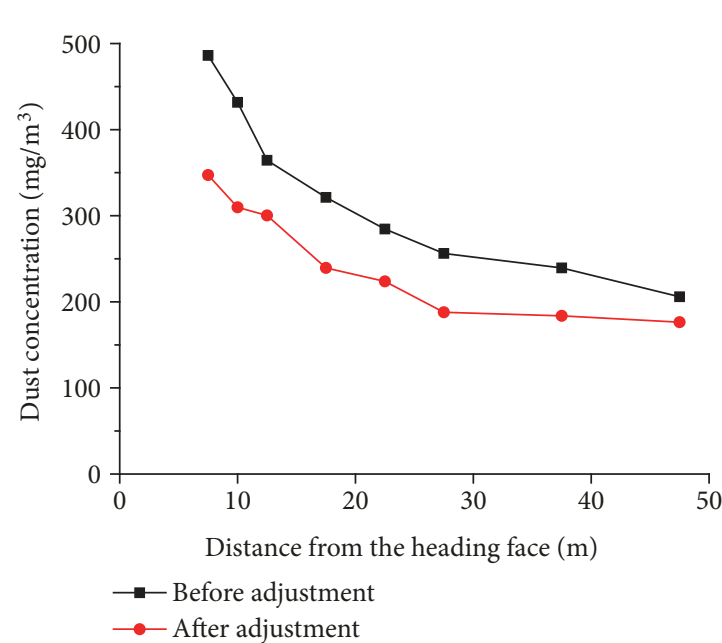

(a)

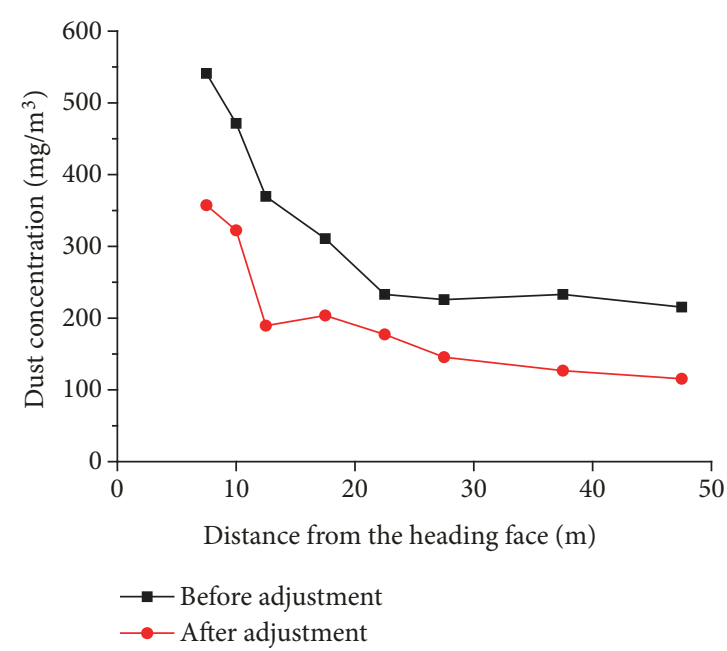

(b)

FIGURE 13: Comparison of dust concentration before and after adjustment at the nearest distance of 5m. (a) Dust concentration along the pedestrian breathing-height. (b) Dust concentration along the driver's breathing-height. 


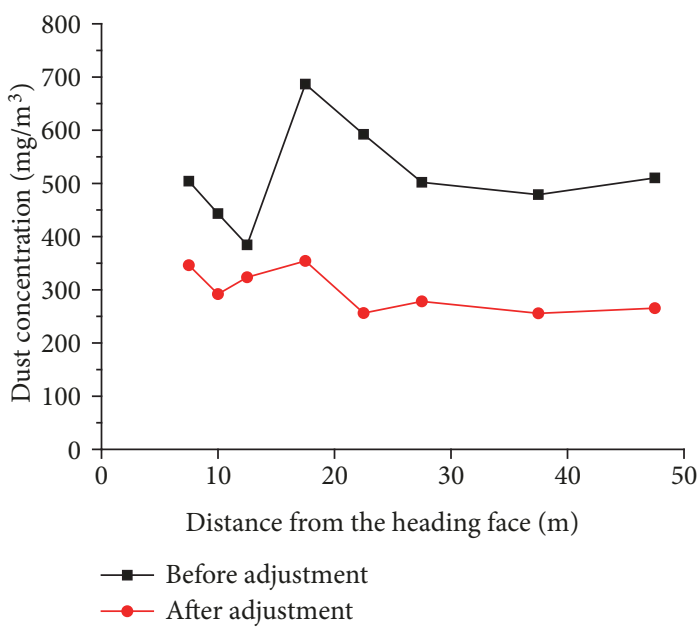

(a)

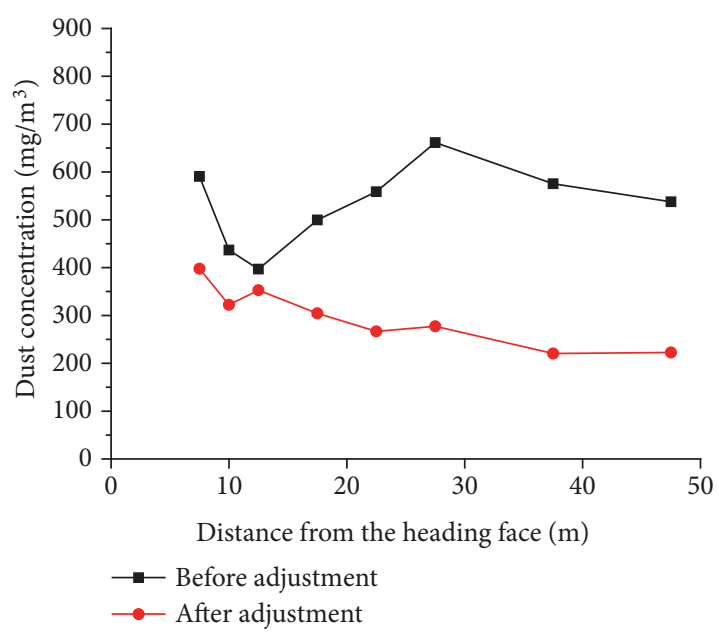

(b)

FiguRE 14: Comparison of dust concentration before and after adjustment at the farthest distance of 10m. (a) Dust concentration along the pedestrian breathing-height. (b) Dust concentration along the driver's breathing-height.

neural network prediction model is established and tested by function with the smallest mean square error. The maximum predicted error is $9.11 \%$, which proves that it can accurately predict dust concentration at the driver location and the pedestrian breathing-height. And the practical application of the double-objective prediction model is carried out.

(3) Taking Ningtiaota coal mine in Northern Shaanxi province of China as the research object, the airflow adjustment schemes are designed, and the established prediction model is used to predict dust concentration under various schemes; then, the optimal adjustment scheme is obtained. At the nearest distance of $5 \mathrm{~m}$, the caliber of $1.1 \mathrm{~m}$, the horizontal right deviation of $15^{\circ}$, and the vertical upward deflection of $6^{\circ}$, dust concentration at the driver location is decreased from $541.1 \mathrm{mg} / \mathrm{m}^{3}$ to $357.4 \mathrm{mg} / \mathrm{m}^{3}$, which is decreased by $34 \%$, and dust concentration at the pedestrian breathing-height in the backflow side decreased from $486.2 \mathrm{mg} / \mathrm{m}^{3}$ to $347.3 \mathrm{mg} / \mathrm{m}^{3}$, which is decreased by $29 \%$. At the farthest distance of $10 \mathrm{~m}$, the caliber of $0.8 \mathrm{~m}$, the horizontal right deviation of $15^{\circ}$, and the vertical upward deflection of $2^{\circ}$, dust concentration at the driver location is decreased to $397.8 \mathrm{mg} / \mathrm{m}^{3}$, and the dust removal effect reached $33 \%$. And dust concentration at the pedestrian breathing-height in the backflow side is decreased to $346.2 \mathrm{mg} / \mathrm{m}^{3}$; the dust removal effect reached $31 \%$ compared with that before adjustment.

\section{Data Availability}

The data used to support the findings of this study are available from the corresponding author upon request.

\section{Conflicts of Interest}

The authors declare that there are no conflicts of interest regarding the publication of this paper.

\section{Acknowledgments}

This research was supported by the National Natural Science Foundation of China (Grant No. 51874235) and Education Department of Province Shaanxi Government Industrialization Cultivation Project (Grant No. 18JC021).

\section{References}

[1] C. Niu, L. Q. Shi, L. L. Xiao et al., "Study on accidents classification of coal mine from 2001 to 2013," Safety in Coal Mines, vol. 46, no. 3, pp. 208-211, 2015.

[2] C. W. Xu, W. Nie, Z. Q. Liu et al., "Multi-factor numerical simulation study on spray dust suppression device in coal mining process," Energy, vol. 182, pp. 544-558, 2019.

[3] H. Q. Wang, S. L. Shi, R. H. Liu et al., "Numerical simulation study on ventilation flow field of wall-attached jet in heading face," Journal of China Coal Society, vol. 29, no. 4, pp. 425-428, 2004.

[4] Q. H. He, "New dust prevention and control technology for fully mechanized heading face," Mining Safety \& Environmental Protection, vol. 35, no. 6, pp. 31-33, 2008.

[5] H. Wang, W. Nie, W. Cheng, Q. Liu, and H. Jin, "Effects of air volume ratio parameters on air curtain dust suppression in a rock tunnel's fully-mechanized working face," Advanced Powder Technology, vol. 29, no. 2, pp. 230-244, 2018.

[6] W. Nie, X. Ma, W. Cheng et al., "A novel spraying/negativepressure secondary dust suppression device used in fully mechanized mining face: A case study," Process Safety and Environmental Protection, vol. 103, pp. 126-135, 2016.

[7] F. Geng, G. Luo, Y. Wang et al., "Dust dispersion in a coal roadway driven by a hybrid ventilation system: A numerical study," Process Safety and Environmental Protection, vol. 113, pp. 388-400, 2018.

[8] Q. Liu, W. Nie, Y. Hua, H. Peng, C. Liu, and C. Wei, "Research on tunnel ventilation systems: dust diffusion and pollution behaviour by air curtains based on CFD technology and field measurement," Building and Environment, vol. 147, pp. 444-460, 2019. 
[9] P. Cai, W. Nie, D. Chen, S. Yang, and Z. Liu, "Effect of air flowrate on pollutant dispersion pattern of coal dust particles at fully mechanized mining face based on numerical simulation," Fuel, vol. 239, pp. 623-635, 2019.

[10] W. Nie, W.-M. Cheng, and G. Zhou, "Formation mechanism of pressure air curtain and analysis of dust suppression's effects in mechanized excavation face," Meitan Xuebao/Journal of the China Coal Society, vol. 40, no. 3, pp. 609-615, 2015.

[11] Y.-C. Li, Z. Li, and L. Gao, "Arrangement of air duct in tunneling working face based on the distribution laws of airflow and dust," Meitan Xuebao/Journal of the China Coal Society, vol. 39, no. 1, pp. 130-135, 2014.

[12] W.-Z. Wang, Y.-M. Wang, G.-Q. Shi et al., "Numerical study on infrared optical property of diffuse coal particles in mine fully mechanized working combined with CFD method," Mathematical Problems in Engineering, vol. 2015, Article ID 501401, 10 pages, 2015.

[13] J. C. Kurnia, A. P. Sasmito, and A. S. Mujumdar, "Dust dispersion and management in underground mining faces," International Journal of Mining Science and Technology, vol. 24, no. 1, pp. 39-44, 2014.

[14] S. Yang, W. Nie, S. Lv et al., "Effects of spraying pressure and installation angle of nozzles on atomization characteristics of external spraying system at a fully-mechanized mining face," Powder Technology, vol. 343, pp. 754-764, 2019.

[15] K. Wang, H. G. Guo, F. Wang et al., "Dust movement rule in ventilators with different diameters in full-mechanized driving face," Coal Mining Technology, vol. 20, no. 5, pp. 80-83, 2015.

[16] Z. Liu, W. Nie, H. Peng, S. Yang, D. Chen, and Q. Liu, "The effects of the spraying pressure and nozzle orifice diameter on the atomizing rules and dust suppression performances of an external spraying system in a fully-mechanized excavation face," Powder Technology, vol. 350, pp. 62-80, 2019.

[17] X. Y. Gong, Z. X. Xia, Y. Wu et al., "Research of dust field optimization distribution based on parameters change of air duct outlet in fully mechanized excavation face of coal mine," in Proceedings of the IOP Conference Series: Earth and Environmental Science, Singapore, 2017.

[18] X. Y. Gong, S. N. Qin, Y. Q. Zhang et al., "Study on optimization of air duct outlet parameters of wind flow field in fully mechanized excavation face of coal mine," Safety in Coal Mines, vol. 48, no. 12, pp. 168-171, 2017.

[19] X. Y. Gong, X. Y. Zhang, Z. X. Xia, Y. Wu, and H. Xue, "Adjustment for the optimum distribution of dust and gas in fully mechanized heading face," Applied Ecology and Environmental Research, vol. 16, no. 4, pp. 4985-5003, 2018.

[20] X. Y. Gong, J. M. Mo, X. Y. Xue et al., "Analysis on influence of fractal characteristics on distribution and settlement of dust flow in heading face ventilation," Coal Technology, vol. 36, no. 9, pp. 112-114, 2017.

[21] X. Y. Gong, Y. J. Hou, K. Zhao et al., "Study on intelligent control device for airflow of air duct outlet in fully-mechanized heading face," Coal Science \& Technology Magazine, vol. 46, no. 12, pp. 814, 2018.

[22] X. Y. Gong, K. Sun, Y. J. Hou et al., "Study on gas concentration prediction model under airflow changes based on neural network in fully mechanized heading face," Mining Research and Development, vol. 39, no. 1, pp. 129-133, 2019.

[23] J. Guo, S. Liu, B. Zhang, and Y. Yan, "Research on virtual machine response time prediction method based on GA-BP neural network," Mathematical Problems in Engineering, vol. 2014, Article ID 141930, 9 pages, 2014.
[24] National Safety Production Supervision and Administration Bureau, Coal Mine Safety Regulations, Coal Industry Press, Beijing, China, 2016.

[25] X. Y. Gong, D. H. Yan, and H. Xue, "Predictive model of excavation ventilation gas concentration in high gas coal mine," Journal of Xi'an University of Science and Technology, vol. 32, no. 3, pp. 275-279, 2012. 


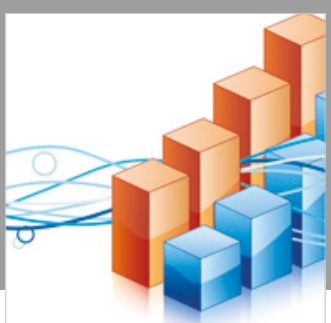

Advances in

Operations Research

\section{-n-m}
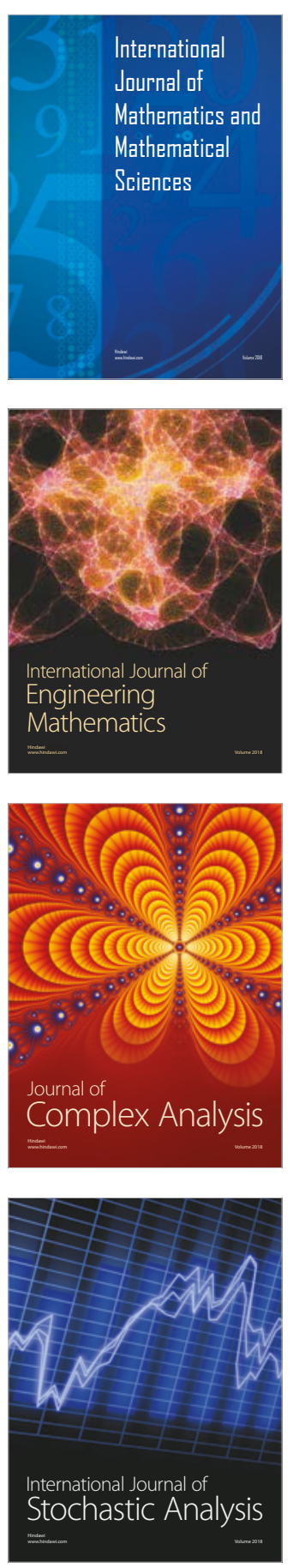
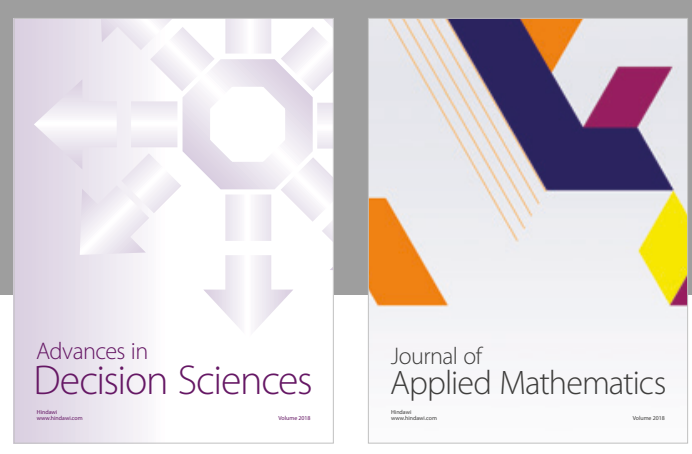

Journal of

Applied Mathematics
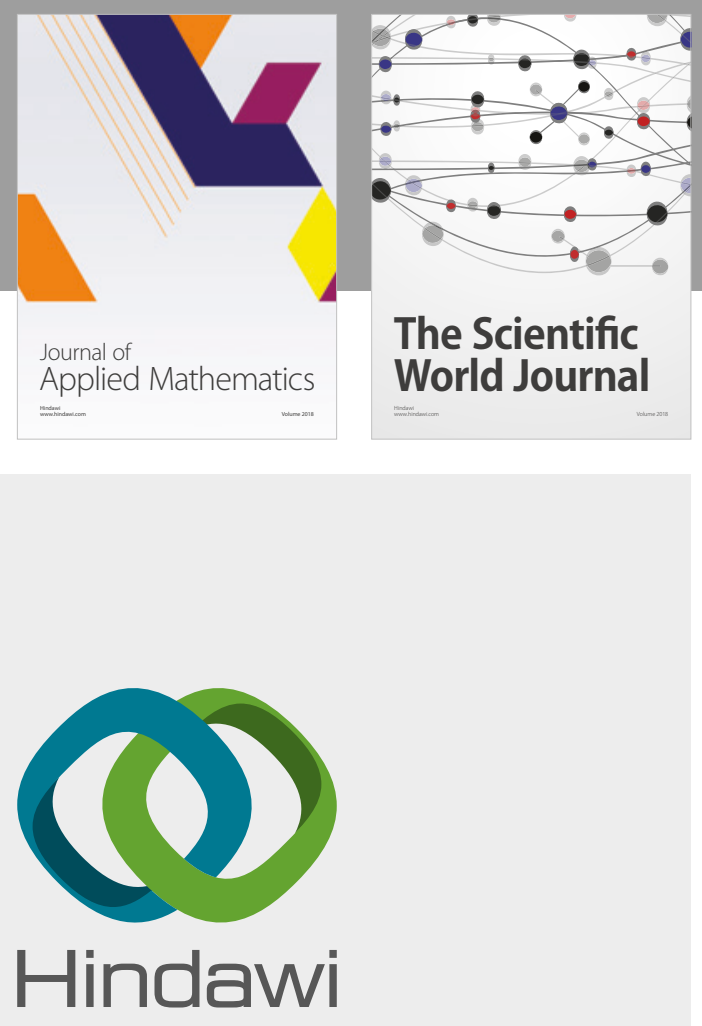

Submit your manuscripts at

www.hindawi.com

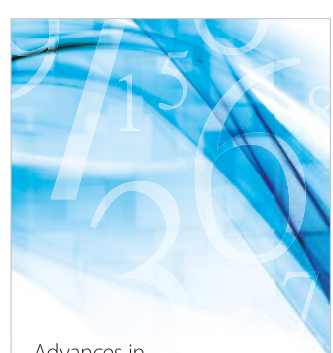

Advances in
Numerical Analysis
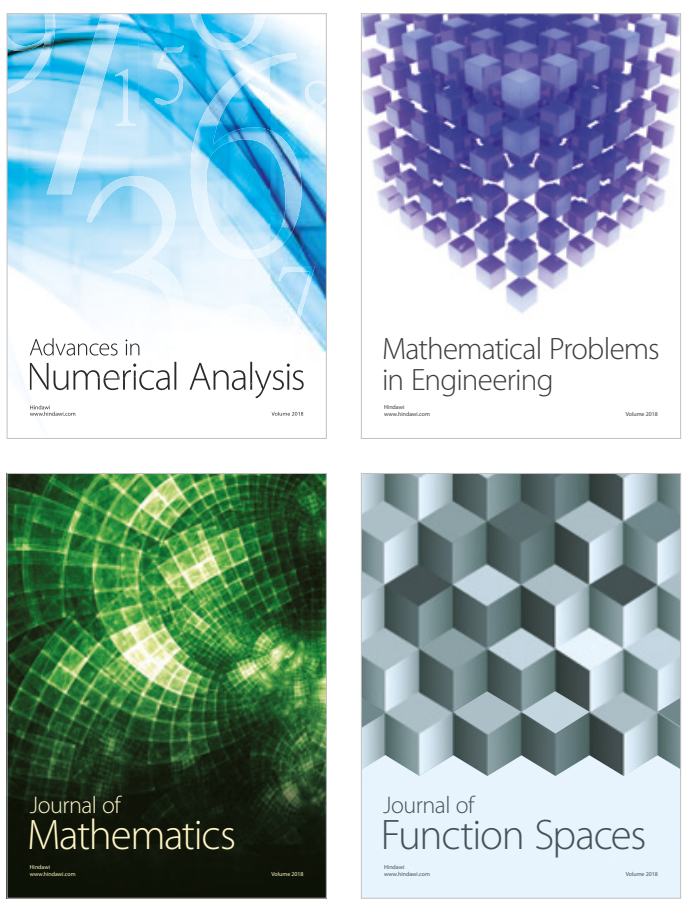

Mathematical Problems in Engineering

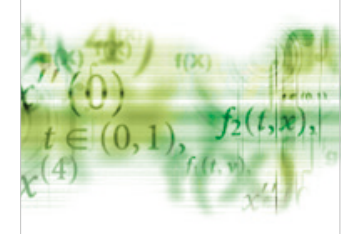

International Journal of

Differential Equations

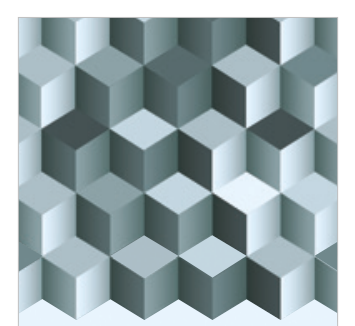

Journal of

Function Spaces

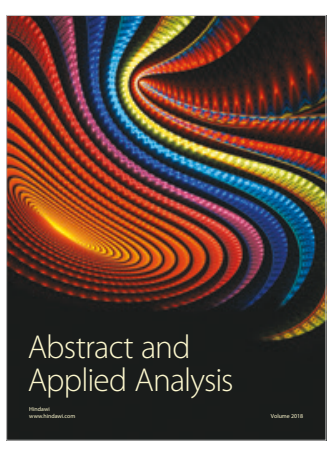

The Scientific

World Journal

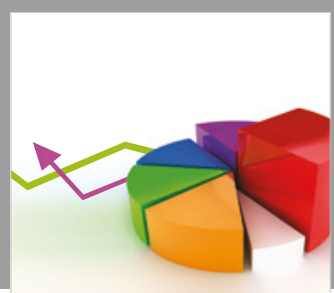

Journal of

Probability and Statistics
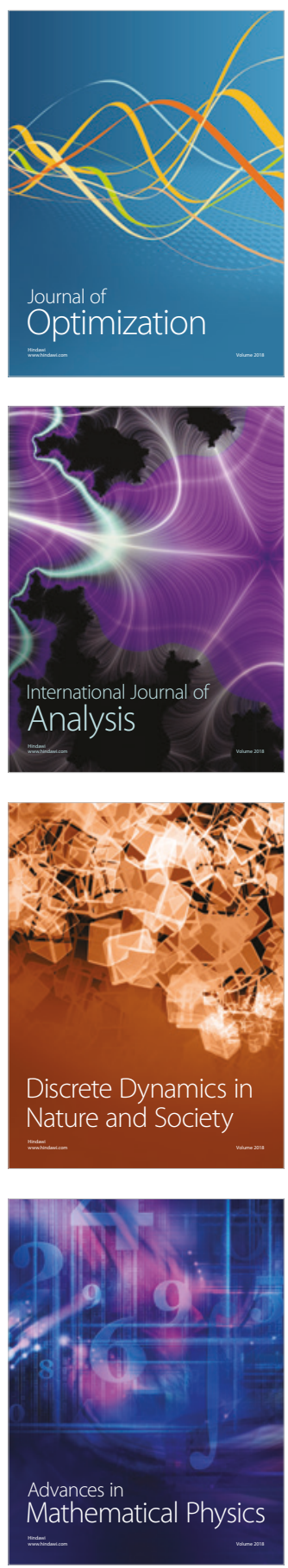